\title{
Modeling Wind Power Curtailment with Increased Capacity in a Regional Electricity Grid Supplying a Dense Urban Demand
}

\author{
Michael Waite ${ }^{1}$, Vijay $_{\text {Modi }}{ }^{1}$ \\ ${ }^{1}$ Department of Mechanical Engineering, Columbia University
}

Corresponding Author: Michael Waite

Email address: mbw2113@columbia.edu

Phone Number: +1 212-854-7993

Postal Address:

Mechanical Engineering Department

Columbia University

220 S. W. Mudd Building

500 West 120th Street

New York, NY 10027 USA 
Many US states have targets for vastly expanding electricity generation from renewable resources. As installed wind capacity increases, several factors can lead to the curtailment of potential wind-generated electricity. Reliably estimating wind power outputs remains a challenge given the dearth of available hub height-altitude wind speed data and measured outputs from newer turbines. A methodology to make such estimates with large increases in wind capacity is described. A regional wind power model, including subroutines for evaluating Statewide grid constraints, and a linear program to solve the model were developed to assess capacity factors and curtailments with deep penetration of wind power into an existing grid under several constrained scenarios implied by demand, baseload generation and transmission. Actual zonal demand and interzonal transmission limits were used for the New York State electricity grid, which has significant potential for wind power mostly distant from the concentrated electricity demand in and around New York City.

The analysis indicates that current wind power outputs in the State underperform when compared to what the potential output should be at the same locations and could be if better wind regime sites were selected. Even with improved selection of sites and turbines, no constraints considered caused curtailment until systemwide capacity exceeds $6 \mathrm{GW}$; beyond this capacity, curtailment occurs only due to the presence of inflexible baseload generators until systemwide capacity exceeds $15 \mathrm{GW}$. At deeper penetrations of wind, mismatches in potential wind power supply and electricity demand coupled with continuously operating baseload generators have the most significant impact on the curtailment of wind-generated electricity, with much of the curtailment occurring during October-March. Interzonal transmission constraints further increase wind curtailment and would require very large transmission capacity increases to capture fully; however, more modest increases in transmission capacity can significantly reduce curtailment.

Keywords: renewable energy resources; wind power; systems integration; urban energy; transmission; baseload generation

\section{Nomenclature}

$\begin{array}{ll}B & \text { baseload electricity generation (MW) } \\ C_{\text {wind }} & \text { total wind turbine capacity at a site (MW) } \\ C F & \text { capacity factor } \\ C F(\text { act }) & \text { actual existing site wind power capacity factor (MWh) } \\ C F^{(N R E L)} & \text { wind power capacity factor, as predicted by NREL wind model data (MWh) } \\ C F^{(p r e d)} & \text { wind power capacity factor, as predicted for existing site turbines at a hub } \\ & \text { height-adjusted wind speed (MW) } \\ c & \text { total installed wind power capacity (MW) } \\ D & \text { electricity demand (MW) } \\ E^{(a c t)} & \text { actual existing site wind-generated electric energy (MWh) } \\ E_{h y d r o} & \text { actual hydroelectric energy (MWh) } \\ h & \text { wind turbine hub height (m) } \\ h_{0} & \text { wind turbine reference hub height (m) }\end{array}$


positive flow transmission limit (MW)

$L^{-}$

l

$N L$

$n_{\text {hrs }}$

reverse flow transmission limit (MW)

$P($ curve-NREL)

transmission line loss factor

net load (MW)

$P$ (forecast)

$P$ (NREL)

$P$ (pred)

$r$
$S_{c a p}$
$S_{z}$
$T$
$t_{s}$
$U$
$v$
$v_{0}$
$W^{*}$
$W^{*}$
$Z$
$\alpha$
$\mu$
$\rho$
$\sigma$
$\tau$

number of hours

wind-generated electric power, as predicted by NREL model manufacturer power curves at a given wind speed (MW)

forecast wind power output (MW)

wind-generated electric power, as predicted by NREL wind model data (MW)

wind-generated electric power, as predicted for existing site turbines at a hub height-adjusted wind speed and actual manufacturer's power curve (MW) wind power scaling factor

set of sites included in analysis for a given systemwide wind capacity

set of sites in a zone

transmission (MW)

time scale for net load ramping calculations (mins)

wind-generated electricity utilized (MW)

wind velocity $(\mathrm{m} / \mathrm{s})$

wind velocity at reference hub height $(\mathrm{m} / \mathrm{s})$

wind power output (MW)

logit transformation of normalized wind power

total number of zones

friction coefficient

mean

Spearman's rank correlation

standard deviation

time step duration (mins)

Subscripts

$\begin{array}{ll}\text { dem } & \text { demand constraint indicator } \\ \text { dem.base } & \text { indicator of combined demand and baseload generator constraints } \\ \text { dem.trans } & \text { indicator of combined demand and transmission constraints } \\ e & \text { existing site index } \\ h & \text { wind turbine hub height (m) } \\ \text { hydro-const } & \text { indicator of the constant hydroelectric baseload generation } \\ m & \text { month } \\ N Y C & \text { New York City } \\ N Y S & \text { New York State } \\ n u C & \text { nuclear } \\ S & \text { NREL site index } \\ t & \text { time step } \\ z & \text { NYISO zone index }\end{array}$




\section{Introduction}

The role of renewable energy sources of electricity to achieve deep reductions in greenhouse gas (GHG) emissions to mitigate the effects of climate change has been welldocumented $[1,2]$. Vast deployment of these technologies - including wind, solar and hydroelectric power, among others not yet representing a significant portion of global energy supply - have been proposed in broad scope GHG emissions reduction studies at global [3], regional [4] and local [5] scales. With some combination of wind and solar power likely to represent a significant majority of new low-carbon electricity generation in most areas, their intermittent availability and output variability will require adaptation throughout the energy delivery system [6], including in transmission networks [7], selection and operation of other generators [8], market design and demand management [9].

Much prior research has evaluated and projected the electricity generation from renewable sources within urban areas, in terms of technology development [10], building integration [11] and resource potential [12]. While identifying opportunities for in-city renewable energy deployment are admirable and perhaps a necessary part of the overall shifting energy landscape, the potential supply is small relative to the electricity demand in a dense urban area. For example, New York City (NYC) is projected to continue to require approximately 33\% of the total annual electricity demand for New York State ("the State") whereas NYC-based renewable energy resources represent $16 \%$ of the Statewide technical potential [13]. The cost of installing such technologies in a dense urban area further reduces the likelihood of relying on this approach for a significant portion of the total renewable electricity supply; NYC-based renewable energy is expected to contribute only $2.2 \%$ of what is deemed economically viable Statewide [13].

Since various United States federal statutes in the late $20^{\text {th }}$ Century (commonly referred to as "deregulation"), the wholesale electricity market is generally managed by an Independent System Operator (ISO) or Regional Transmission Organization (RTO) [14]; New York State became one of the early adopters of the new approach. A detailed review of the design and operation of these markets can be found elsewhere [15]; however, the increase in these organizations and similar market structures outside the US led to more rapid development of computational models of electricity markets [16].

We are interested in a particular situation that demonstrates the challenges as progressively less desirable sites are selected for renewable resource deployment [17]: Expansion of large-scale wind power in a regional electricity grid. The region corresponds to a "balancing authority" identified in the National Renewable Energy Laboratory (NREL) Eastern Wind Integration and Transmission Study (EWITS) [18], a particularly broad-scope study of potential wind power in the U.S. from the Great Plains to the Atlantic Coast. That study identified long-distance, high-capacity transmission from the Plains to the Midwest and East as the primary means of improving the economics of large-scale wind power, but did include 8-24 GW of on-shore wind power in the New York ISO (NYISO). However, the NYISO region was treated as a single zone in [18], despite unique intraregional challenges caused by zonal demand, existing baseload generators and interzonal transmission limits 
with potential wind power sites mostly distant from the concentrated electricity demand in and around New York City.

This paper examines the effect of adding up to $37.5 \mathrm{GW}$ of wind capacity to the New York State electricity grid (with particular emphasis on 10, 20 and $30 \mathrm{GW}$ scenarios). Specifically, the expected curtailment was analyzed assuming existing transmission and baseload generators remained as expected in the timeframe that large-scale wind power might be deployed, as well as by eliminating or reducing those constraints. Seasonal curtailment effects, relative impact of constraints included in combination with others and increases in transmission capacity were also evaluated. Several new methods, relying on extensive data sets, are developed to improve the accuracy of the model used in the analyses described herein. The paper is organized to first describe the reasoning behind the approach and network data used (Section 2). The following sections describe the methodology used to develop the wind power time series model (Section 3) and for the power flow analysis (Section 4). Section 5 presents pertinent results and our interpretation of them. Section 6 discusses the implications of the findings, and Section 7 summarizes our conclusions, as well as plans and needs for further research.

There are several technical challenges related to connecting large-scale wind power to an existing electricity grid; however, we primarily focus on real power flow considerations. The paper does not address a) how operational strategies to determine unit commitments in the future and forecasting limitations could potentially further increase curtailment [19] and b) how actual market design and operation might also change the way resources are allocated [20-22].

\section{Approach overview}

Regardless of the structure of an electricity market, some form of the unit commitment problem (UCP) is solved to determine which generators are used to meet electricity demands by minimizing the cost of system operation [23]. ISOs and RTOs typically operate a day-ahead hourly electricity market and a higher time-resolution (e.g. 5 minute resolution) "real-time" electricity market, as well as reserve and regulation markets. Typically, proprietary software tools are used to solve the UCP for these markets; however, extensive research into methodologies and solutions has been conducted in academia, as well [24], and other optimization approaches are being developed [25-27]. The increased interest in integrating large capacities of variable renewable energy into the power system has led to efforts to account for uncertainty in the UCP by incorporating stochastic optimization using Lagrangian relaxation [28] and adaptive modeling techniques [29]. However, a deterministic mixed integer linear program (MILP) remains widely used, is sufficient for market operation modeling and is a consistent methodology well-documented in the literature [30,31].

In an earlier study [32], we employed a similar MILP methodology to model the State electricity grid operated by the New York Independent System Operator (NYISO). In the earlier study, daily one-hour time resolution MILP determines the generator mix that minimizes total daily fuel cost required to meet the State's electricity demands; it includes 
all generators connected to the NYISO-operated grid and all interzonal transmission constraints. In that study, hourly GHG emissions for the State electricity grid are modeled over a single year, and the results showed good agreement with actual fuel demands at a macro scale (monthly usage by fuel type and zone). A limitation of that model is, the long run times of MILPs that can make parametric analyses unrealistic given computational constraints.

The explicit modeling of all generators, and the computational complexity it presents, would not have been needed for the questions we try to address here. In order to avoid runtime issues and allow exploration of a large number of scenarios, explicit models for the thermal generators are removed, allowing the model to be reduced to a linear program (LP) solved at each time step to minimize net loads after low-to-no GHG emission electricity is utilized.

The primary goal of this paper is to examine the effect of deep penetration of wind into the State grid, while making some idealizations about how the rest of the load is met. In order to compute the curtailment under different scenarios, increasing amount of installed wind capacity is installed, while modeling the rest of the generation system as constraints on the utilization of potential wind-generated electricity.

The following scenarios will be considered

- Scenario A - Unconstrained: No wind-generated electricity is curtailed (Described in detail in Section 4.1)

- Scenario B - Demand Constraint: Wind-generated electricity is curtailed if there is no corresponding systemwide demand. (Section 4.2)

- Scenario C - Demand Constraint + Baseload Generation: Wind-generated electricity is curtailed if there is no corresponding systemwide net load after applying systemwide baseload generation. (Section 4.3)

- Scenario D - Zonal Demand + Transmission Limits: Linear program optimization is performed at each time step; includes zonally-distributed demand and windgenerated electricity supply, as well as interzonal transmission limits. (Section 4.4)

- Scenario E - Zonal Demand + Baseload Generation + Transmission Limits: Linear program optimization is performed at each time step; includes zonally-distributed demand, baseload generation and wind-generated electricity supply, as well as interzonal transmission limits. (Section 4.4)

The analytical approach outlined in this paper required several types of data: Network geography and interzonal transmission constraints; zonal electricity demand time series; wind power output time series and geospatial information; and baseload generator capacity.

Due to the available time spans of some datasets and to avoid complications from daylight savings time, all analyses were performed for Coordinated Universal Time (UTC). Therefore, the time range of the analysis (1 January 2007 00:00 - 31 December 2012 
23:55) covers the local New York time 31 December 2006 19:00 - 31 December 2012 18:55. The following subsections describe how these data were accessed, cleaned, prepared and synthesized for this effort.

\subsection{NYISO network topology}

The New York Independent System Operator (NYISO) is responsible for operating a regional electricity market that aligns with the boundaries of the State. NYISO organizes the State into 11 zones, as shown in Fig. 1; New York City is Zone J.

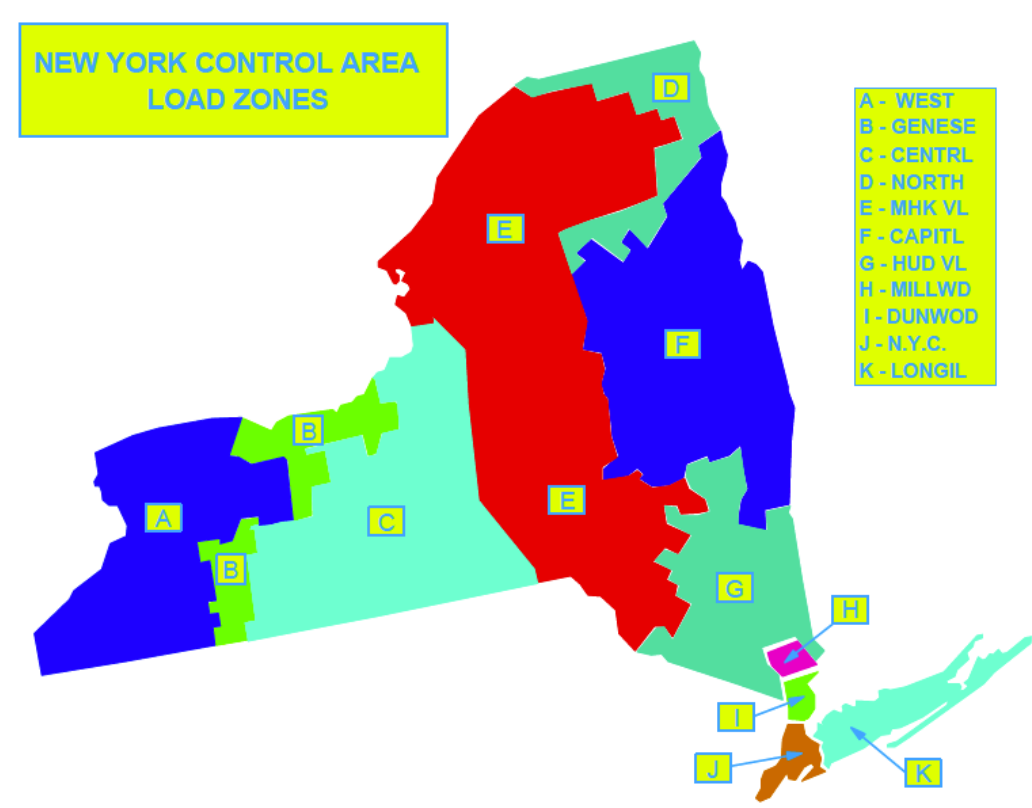

Fig. 1. NYISO zone map (Source: NYISO)

NYISO also documents transmission lines within the State and between NYISO and adjacent control areas (i.e. other independent system operators). Depending on operating conditions, system maintenance, weather and many other factors, the power flow limits on individual transmission lines and across major interfaces is not necessarily constant throughout the year. For the purposes of the analyses outlined in this paper, the interzonal limits were the same as those used for the NYISO's 2016 system reliability simulations [33].

\subsection{Zonal demand data}

NYISO publishes real-time load data by zone in 5 minute time increments (with some additional miscellaneous values that do not conform to the 5 minute time step) [34]. The analysis described in this paper used 5-minute time resolution demand data for the 11 NYISO load zones for the years 2007-2012; a total of 631,296 demand data points for each zone.

The raw data from NYISO contained some missing values as summarized for all zones in Appendix Table A1; however, for no zone did the number of missing data points exceed 
$0.015 \%$ of the total number of 5 -minute demand values over the 6-year analysis period. As such, any assumptions required to complete the zonal time series are not expected to have a significant impact on the results of the analysis.

These missing points and data gaps were filled in by linear interpolation of the demand data for the time step preceding the first missing point in the data gap and the time step following the last missing point in the data gap. For all zones, there were a small number of gaps slightly longer than one 5-minute time step: Five gaps of two time steps, one gap of three time steps and one gap of four time steps. One longer gap of 20 time steps (100 minutes) required interpolation; however, this is expected to have an insignificant effect on the six-year analysis.

Table 1 summarizes representative characteristics of the demand in each zone for the sixyear analysis period.

Table 1. Summary of NYISO zone demand data

\begin{tabular}{|c|c|c|c|c|c|c|}
\hline Zone & $\begin{array}{c}\text { Average } \\
\text { Demand } \\
\text { (MW) }\end{array}$ & $\begin{array}{c}\text { \% Statewide } \\
\text { Average } \\
\text { Demand }\end{array}$ & $\begin{array}{c}\text { Peak } \\
\text { Demand } \\
\text { (MW) }\end{array}$ & $\begin{array}{c}\text { \% Statewide } \\
\text { Peak } \\
\text { Demand }\end{array}$ & $\begin{array}{c}\text { Minimum } \\
\text { Demand } 3 \\
(\mathrm{MW})\end{array}$ & $\begin{array}{c}\text { \% Statewide } \\
\text { Minimum } \\
\text { Demand }\end{array}$ \\
\hline $\mathrm{A}$ & 1801 & $9.7 \%$ & 2940 & $7.5 \%$ & 1113 & $14 \%$ \\
\hline $\mathrm{B}$ & 1147 & $6.2 \%$ & 2209 & $6.0 \%$ & 604 & $8.4 \%$ \\
\hline $\mathrm{C}$ & 1866 & $10 \%$ & 3074 & $8.6 \%$ & 1132 & $13 \%$ \\
\hline $\mathrm{D}$ & 671 & $3.6 \%$ & 1113 & $2.3 \%$ & 173 & $7.0 \%$ \\
\hline $\mathrm{E}$ & 897 & $4.8 \%$ & 1531 & $4.2 \%$ & 223 & $5.3 \%$ \\
\hline $\mathrm{F}$ & 1315 & $7.0 \%$ & 2442 & $6.6 \%$ & 716 & $8.9 \%$ \\
\hline $\mathrm{G}$ & 1180 & $6.3 \%$ & 2455 & $7.1 \%$ & 180 & $4.7 \%$ \\
\hline $\mathrm{H}$ & 331.3 & $1.8 \%$ & 1036 & $2.1 \%$ & 1 & $1.0 \%$ \\
\hline $\mathrm{I}$ & 695.0 & $3.7 \%$ & 1532 & $4.4 \%$ & 164 & $2.9 \%$ \\
\hline $\mathrm{J}$ & 6184 & $33 \%$ & 11,479 & $34 \%$ & 2848 & $30 \%$ \\
\hline $\mathrm{K}$ & 2567 & $14 \%$ & 5947 & $18 \%$ & 431 & $4.7 \%$ \\
\hline Statewide & 18,655 & $100 \%$ & 33,956 & $100 \%$ & 9685 & $100 \%$ \\
\hline
\end{tabular}

${ }^{1}$ These values are for the six-year analysis period, 2007-2012

${ }^{2}$ This value represents the contribution of each zone to the peak State demand at the time of the peak State demand; it may not correspond to the value in the "Peak Demand" column for each zone, which may occur at different times.

${ }^{3}$ Some minimum values appear anomalous as large power outage occurred during a hurricane in 2012. ${ }^{4}$ This value represents the contribution of each zone to the minimum State demand at the time of the minimum State demand; it may not correspond to the value in the "Minimum Demand" column for each zone, which may occur at different times.

\section{Wind power model}

In order to evaluate the effects of deeper penetration of wind power in the State electricity grid, a time series of wind power outputs at specific geographical locations was required. A data set was identified to serve as a basis for our wind power model (Section 3.1). Analysis of the model and actual wind-generated electricity from existing wind sites indicated 
higher-than-expected wind power capacity factors (Sections 3.1.1-3.1.3). As such, an adjustment procedure was developed to more accurately reflect the expected electricity production from wind sites (Section 3.1.4). All NREL model wind sites in the State were then identified, allocated to NYISO zones and the adjustment procedure from Section 3.1.4 was applied (Section 3.2).

\subsection{NREL model and adjustments to NREL wind site data}

The National Renewable Energy Laboratory (NREL) has developed a set of meteorological and wind power production time series data using a model developed and evaluated on a grid overlaying the continental US: the Wind Integration National Dataset (WIND) Toolkit [35].

The 5-minute resolution data is available for the years 2007-2012 for 126,000 potential onshore and off-shore wind sites nationwide identified by NREL. Site location is provided and capacity at each site grid cell is between one and eight $2 \mathrm{MW}$ wind turbines. As this is by far the most comprehensive dataset available for wind integration analyses, this data was used as the basis for the analyses described in Section 4 of this paper. While according to NREL, the model meteorological data generally showed good agreement with observations [36], the agreement between model and actual output wind power was not as good [37]. Hence, in this paper we have adjusted the NREL model wind power output to more closely reflect generation from existing wind power sites.

NREL model-predicted power output and actual monthly wind site output (available from EIA [38]) from existing wind sites are both available for the most recent complete year of 2011. Excluding those sites that became operational during 2011, we were left with 15 existing sites in the State (with a total rated capacity of $1274 \mathrm{MW}$ ).

The following data and corrections were used to calculate monthly electricity output and compared to the actual monthly electricity generated at each site:

1. NREL provided wind speed and power output (based on specified manufacturer power curves or MPC), at $100 \mathrm{~m}$ hub height and operation assumed to be without forced outages. These MPCs generally happen to be for newer and more efficient turbine models than those actually installed. In Section 3.1.1 we describe how the five-minute power output from each site is used to compute monthly and annual site capacity factors.

2. In Section 3.1.2, five-minute wind-speed data from NREL are adjusted to actual hub heights of existing installations while preserving the difference between NREL predicted power and MPC-based power output. New capacity factors are then computed.

3. NREL-assumed MPCs are replaced with MPCs for actual turbines installed at existing sites, and capacity factors from (2) are recomputed in Section 3.1.3.

4. The capacity factors computed in (3) remain significantly higher than those from actual electricity generated at each site from EIA [38]. Section 3.1.4 describes the 
methodology adopted to allow a significantly improved agreement with actual capacity factors.

The wind turbines' MPC included in NREL's System Advisor Model [39] were used in the analysis described in Section 3.1.2, corresponding to Item 2 in the "data and corrections" list above. Wind turbines and hub heights for existing installations were assumed based on information for each site in an online database of wind farms [40]. Appendix Table A2 summarizes information used for this analysis of the 15 existing sites; the wind sites and turbine manufacturers and models have been anonymized.

\subsubsection{Computing capacity factors from NREL model}

The NREL model-predicted wind power output at $100 \mathrm{~m}$ hub height, $P_{100, e, t}^{(N R E)}$, at time, $t$, for the nearest NREL sites adding up to total capacity at the existing site, $e$, was aggregated by month to calculate the total wind-generated electricity for month, $m$. The NREL modelpredicted monthly capacity factor, $C F_{100, e, m}^{(N R E)}$, was then calculated for each site by dividing the wind-generated electricity by the product of total wind turbine capacity, $C_{\text {wind }}$, at each site and the number of hours, $n_{h r s}$ :

$$
C F_{100, e, m}^{(N R E L)}=\frac{\sum_{t \in m} P_{100, e, t}^{(N R E L)}}{n_{h r s, m} \times C_{\text {wind }, e}}
$$

\subsubsection{NREL hub height-adjusted model}

Wind speed data for each 5 minute time step from the nearest NREL sites adding up to total capacity at the existing site was scaled using the power law approach [41]:

$$
\frac{v}{v_{0}}=\left(\frac{h}{h_{0}}\right)^{\alpha}
$$

where $v$ is the velocity at hub height, $h, v_{0}$ is the NREL model wind speed at the $100 \mathrm{~m}$ reference hub height, $h_{0}$, and $\alpha$ is the friction coefficient. The surrounding landscape of each site was unknown, so a friction coefficient of 0.20 was assumed for all sites; this value corresponds to "high crops, hedges and shrubs" [41]. Interpolation of the NREL wind turbine MPC [35] was used to calculate the MPC-predicted power output of each wind turbine at the $100 \mathrm{~m}$ hub height at each time step. The specific MPC used depended on the International Electrotechnical Commission (IEC) classification [42] of the wind regime at that site, as identified by NREL; see Appendix Table A3 for this MPC data.

The NREL model power output accounts for some site effects that reduce power output below the MPC-predicted value. A linear scaling factor of the ratio, $r_{e, t}$, of the NREL model 
power output at $100 \mathrm{~m}, P_{100, e, t}^{(N R E L)}$, to the NREL MPC-predicted output at $100 \mathrm{~m}, P_{100, e, t}^{(c u r v e-N R E L)}$, was calculated for each site and time step:

$$
r_{e, t}=\frac{P_{100, e, t}^{(N R E L)}}{P_{100, e, t}^{(c u r v e-N R E L)}}
$$

The NREL turbine MPC was then used to calculate the MPC-predicted power output at the turbines' actual hub height, $P_{h, e, t}^{(\text {curve-NREL) }}$. These values were then scaled by $r_{e, t}$ and aggregated by month to calculate each site's monthly wind-generated electricity. Each site's monthly NREL model-predicted capacity factor at the existing site's hub height, $C F_{h, e, m}^{(N R E L)}$, was then calculated by:

$$
C F_{h, e, m}^{(N R E L)}=\frac{\sum_{t \in m} r_{e, t} \times P_{h, e, t}^{(\text {curve-NREL })}}{n_{h r s, m} \times C_{\text {wind }, e}}
$$

\subsubsection{Adjusting for manufacturer turbine specifications}

The MPC data for the wind turbines at existing sites [40] are included in Appendix Table A4. The MPC for each existing site was used with the NREL model wind speed time series to calculate the predicted model power output for the actual wind turbine, $P_{h, e, t}^{(\text {curve })}$. These values were then scaled by $r_{e, t}$ : and aggregated by month to calculate each site's predicted monthly wind-generated electricity. The NREL model-predicted monthly capacity factor at each existing site's hub height, $C F_{h, e, m}^{(\text {pred })}$, was then calculated by:

$$
C F_{h, e, m}^{(\text {pred })}=\frac{\sum_{t \in m} r_{e, t} \times P_{h, e, t}^{(\text {curve })}}{n_{h r s, m} \times C_{\text {wind }, e}}
$$

\subsubsection{Correcting model-based power output for actual electricity generated}

The monthly wind-generated electricity reported for each site to the EIA (see the beginning of Section 3.1), $E_{e, m}^{(a c t)}$, was used to calculate the actual monthly capacity factor, $C F_{h}^{(a c t)}$ :

$$
C F_{e, m}^{(a c t)}=\frac{E_{e, m}^{(a c t)}}{n_{h r s, m} \times C_{\text {wind }, e}}
$$

The monthly CFs for the scenarios described in Sections 3.1.1-3.1.3 were then compared to the actual wind-generated electricity CFs at each site; these monthly comparisons are 
shown in Appendix Fig. A1. The NREL model, adjusted for the correct hub height and turbine for each site generally over-predicts the $\mathrm{CF}$ when compared to the actual output at the sites. In some cases, the monthly CF predicted by the model exceeds two times the actual $\mathrm{CF}$ in a month. Even in scenarios where the $\mathrm{CF}$ in a given month is near the actual $\mathrm{CF}$ in that month, the predicted systemwide wind-generated electricity is higher than the actual CF. This can be seen in the annual CFs for each site, which are shown in Fig. 2.

The monthly and annual CFs both indicate that the hub height adjustment has a fairly small impact, particularly when compared to the effect of using the actual turbine MPC. Further, the impact of hub height does not vary much month-to-month and, thus, with changes in wind speed. Therefore, further modifying the friction coefficient, $\alpha$, is not expected to significantly alter the calculations shown in Fig. 2 or in the Appendix Fig. A1. This was confirmed by varying the friction coefficient and reviewing the results. No correlation was found between the accuracy of CF predictions and the age of the wind turbines, turbine manufacturer/model, hub height, wind class or site location.

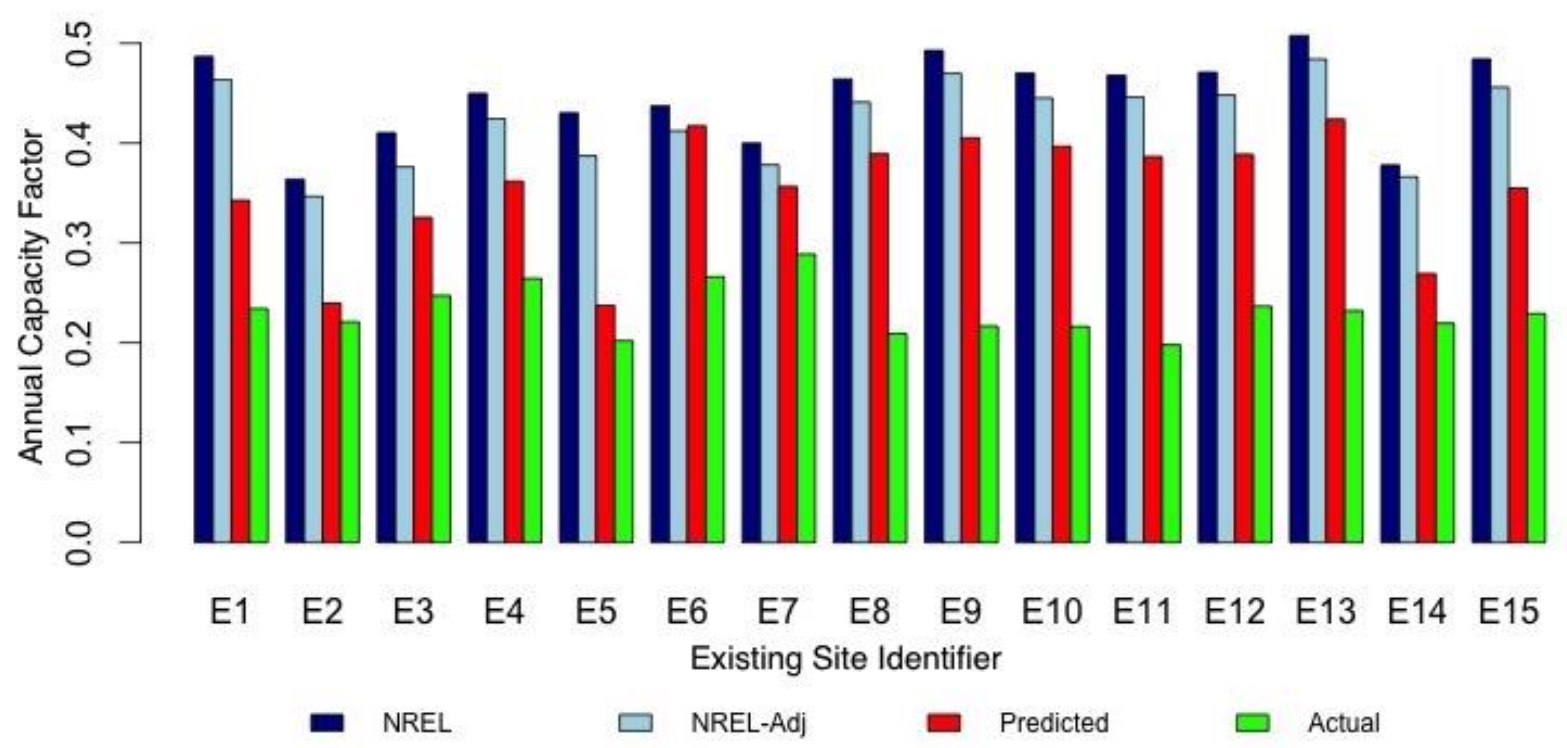

Fig. 2. Annual capacity factors of existing wind power sites

One simple way to adjust turbine performance, characterized by a capacity factor, would have been to proportionally change turbine output at each time step using a constant correction factor based on the annual ratio of actual to model energy generation. Such a linear scaling however would lead to erroneous seasonal corrections, peak power and fluctuations (all important to modeling grid penetration), and would not accurately capture the nonlinear relationship between wind turbine output and wind speed.

The methodology for the correction used in this study was borrowed from Mauch et al [43] where it was used to model systemwide wind power forecast uncertainties for ISOs and RTOs. Adapting the methodology of [43] allows one to make corrections while ensuring that (a) the wind power output remains bound by the peak power output and (b) the nonlinear behavior of the turbine MPC is captured. Our adaptation of the methodology 
otherwise detailed in [43], is reported in this paper's online supplemental material. However, some general parameters are needed in order to describe the remainder of our analytical approach.

The correction methodology requires a logit transformation of wind power output generalized as:

$$
P^{*}=\ln \left(\frac{P / C_{\text {wind }}}{1-P / C_{\text {wind }}}\right)
$$

where $P$ is some power output and $C_{\text {wind }}$ is the total wind power capacity. We first calculate the total predicted systemwide wind power output at each time step, $t$, as determined from the NREL model power output adjusted per Section 3.1.3, $P_{h}^{(\text {pred })}$, at each site, $e$ :

$$
W_{t}^{(\text {pred })}=\sum_{e=1}^{15} P_{h, e, t}^{(\text {pred })}
$$

Using the methodology of [43], a bivariate normal distribution is defined by the mean, $\mu$, and standard deviation, $\sigma$, of the transformed normalized systemwide wind power output, $W^{*}$, given a normalized NREL model-predicted systemwide wind power output, $W_{t}^{(\text {pred })^{*}}$,for each time step, $t$ :

$$
\begin{gathered}
\mu_{W_{t}^{*} \mid W_{t}^{(\text {pred })^{*}}}=\beta_{1}+\beta_{2} W_{t}^{(\text {pred })^{*}} \\
\sigma_{\left.W_{t}^{*} \mid W_{t}^{(p r e d}\right)^{*}}=\beta_{3}
\end{gathered}
$$

where $\beta_{1}, \beta_{2}$ and $\beta_{3}$ are constants. Here, the transformed wind power output, $W^{*}$, is not yet known. However, a necessary step in the process of adjusting the output of the NREL model is the transformation of $W^{*}$ to the real space, using the inverse of Eq. (7), and scaling by the site's wind power capacity:

$$
W_{t}=\left(\frac{1}{1+e^{-W_{t}^{*}}}\right) C_{\text {wind }}
$$

A nonlinear model was developed to determine the values for $\boldsymbol{\beta}=\left(\beta_{1}, \beta_{2}, \beta_{3}\right)$ that minimize the least-squares estimates of the systemwide monthly $\mathrm{CF}$, with the following objective function: 
The optimization problem in Eq. (12) was solved using the package "nls2" [44] in R [45]; the solution to was $\boldsymbol{\beta}=(-1.094,0.7642,0.4446)$. The root-mean-square-deviation (RMSD) between the actual monthly CFs and the estimated monthly CF values using this bivariate normal distribution adjustment was 0.013 ( $5.7 \%$ of the annual CF). This is significantly better than the RMSD of the refined NREL model-predicted values: 0.152 (63.7\% of the annual CF). Fig. 3 shows the systemwide wind power CF for each month for the actual site performance, the adjusted NREL model (Section 3.1.3) and the final model using the bivariate normal distribution adjustment.

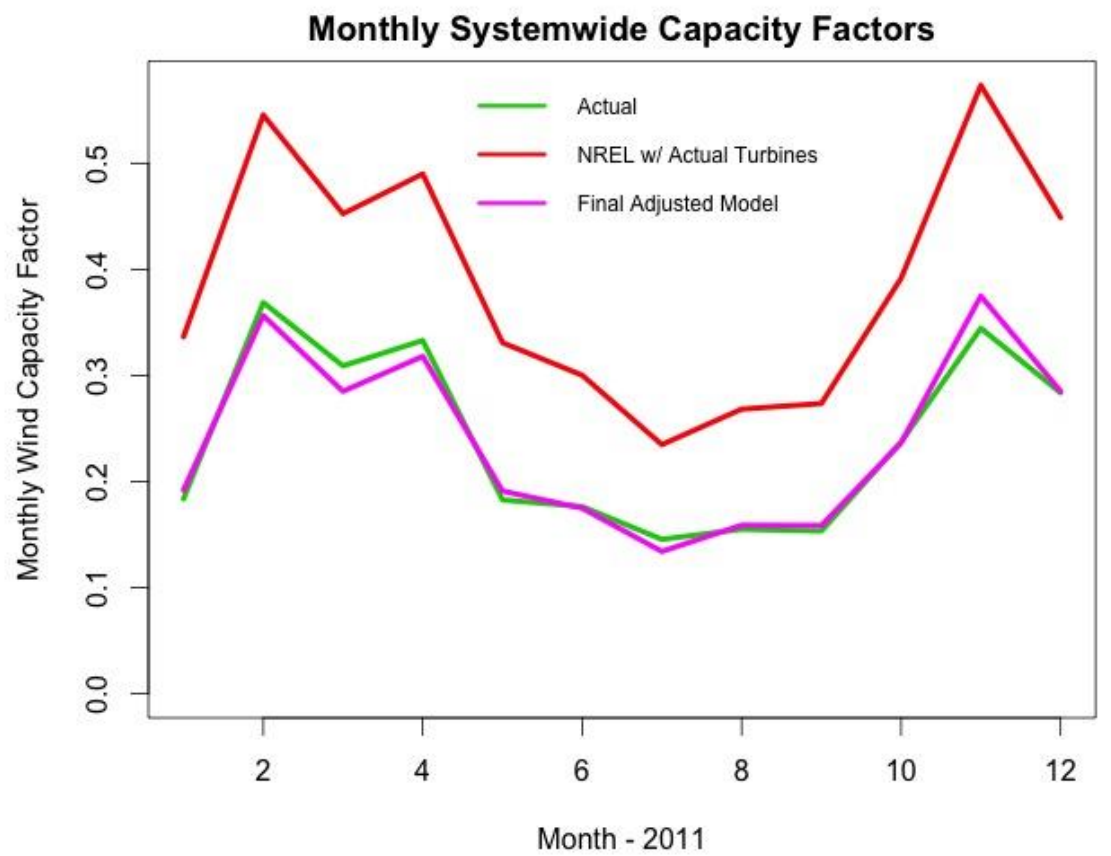

Fig. 3. Monthly capacity factors - predicted and actual

\subsection{New York State potential wind power sites and simulated power output}

For significantly expanding wind penetration, one would need to consider locations beyond those where turbines are currently located. In this section, a five-minute wind power output model is developed for New York State, at locations for potential wind sites identified in the NREL data set; it's possible that some potential wind farm sites in the State are not included in this data set. Using publicly available shapefiles for civil boundaries of cities and towns [46], along with identifying the cities' and towns' respective NYISO control 
zones, shapefiles for each zone are created ${ }^{1}$. Fig. 4 shows the result of this process with a blue point representing each potential wind power site.

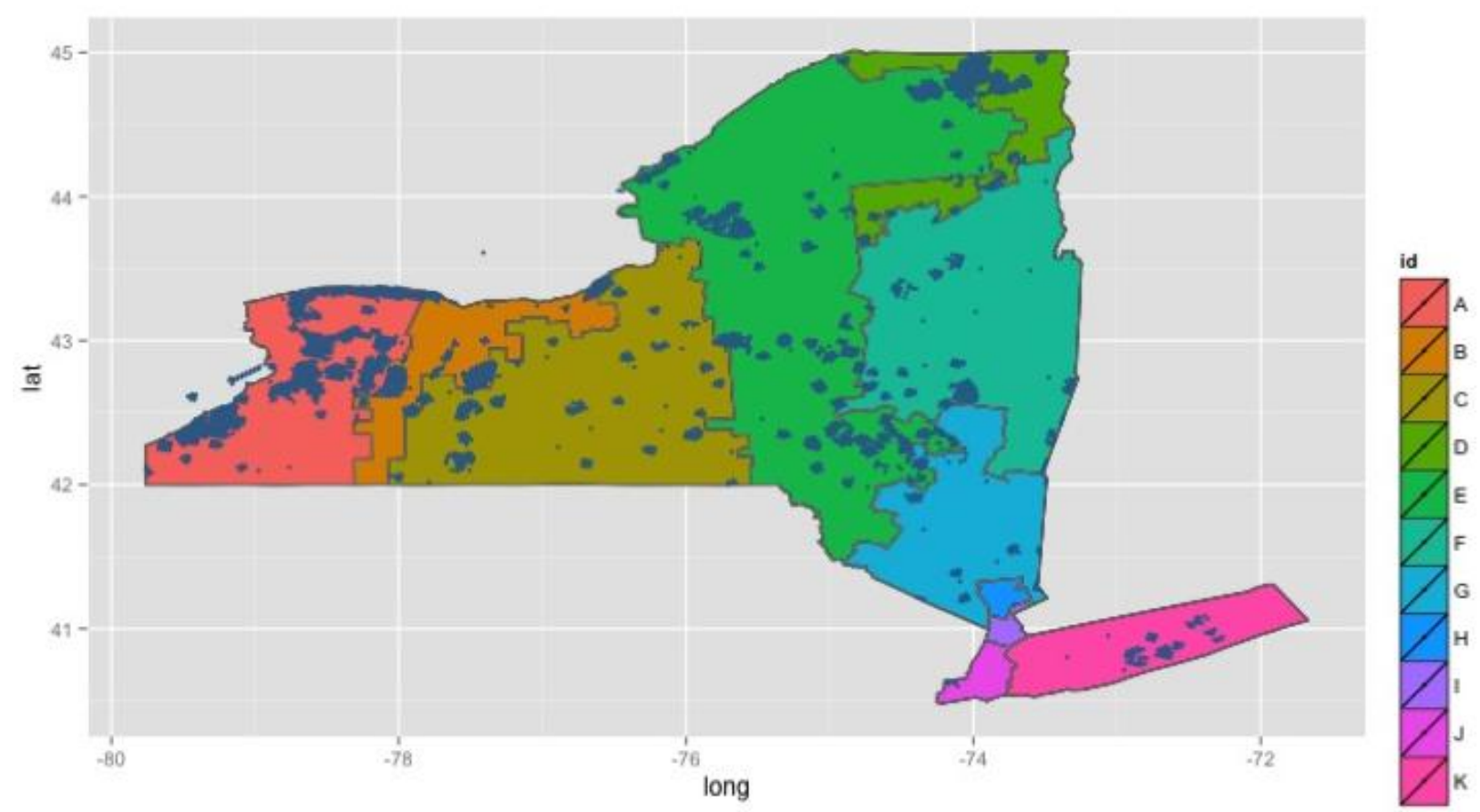

Fig. 4. NYISO zonal map with potential wind power sites

For all of the new sites, adjustments as described in Section 3.1.4 are applied. Table 2 summarizes average annual electricity generation potential and capacity factors for each zone and for the State as a whole over the six-year data period; the "Base NREL Model" refers to the power outputs directly from the NREL data set (Section 3.1.1) and the "Final Adjusted Model" refers to the data set after the adjustments described in Section 3.1.4.

1 This is a composite developed by the authors, so it does not necessarily overlay exactly on the NYISO zone map. Geospatial data for the NREL wind sites was overlaid on the zonal geometry to identify the zones to which each potential NREL site corresponded. The geospatial data for the NREL wind data sites was then used to identify potential sites in the State and to assign them to the NYISO zone in which they are located. 
Table 2. Summary of full NREL wind data set and final adjusted model by NYISO zone

\begin{tabular}{|c|c|c|c|c|c|}
\hline \multirow{2}{*}{ Zone } & \multirow{2}{*}{$\begin{array}{c}\text { Total Wind } \\
\text { Capacity (MW) }\end{array}$} & \multicolumn{2}{|c|}{$\begin{array}{c}\text { Average Annual Potential } \\
\text { Electricity Generation (TWh) }\end{array}$} & \multicolumn{2}{|c|}{ Capacity Factor } \\
\hline & & $\begin{array}{c}\text { Base NREL } \\
\text { Model }\end{array}$ & $\begin{array}{c}\text { Final Adjusted } \\
\text { Model }\end{array}$ & $\begin{array}{l}\text { Base NREL } \\
\text { Model }\end{array}$ & $\begin{array}{l}\text { Final Adjusted } \\
\text { Model }\end{array}$ \\
\hline $\mathrm{A}$ & 11,746 & 43.1 & 31.2 & 0.416 & 0.265 \\
\hline $\mathrm{B}$ & 2018 & 7.72 & 5.80 & 0.436 & 0.281 \\
\hline $\mathrm{C}$ & 4886 & 18.1 & 13.1 & 0.422 & 0.262 \\
\hline $\mathrm{D}$ & 3000 & 11.9 & 8.64 & 0.451 & 0.282 \\
\hline $\mathrm{E}$ & 10836 & 40.8 & 29.0 & 0.429 & 0.262 \\
\hline $\mathrm{F}$ & 3170 & 11.8 & 8.36 & 0.425 & 0.259 \\
\hline$G$ & 1032 & 4.14 & 2.99 & 0.457 & 0.283 \\
\hline $\mathrm{H}$ & 16 & 0.054 & 0.043 & 0.387 & 0.262 \\
\hline I & 0 & 0 & 0 & NA & NA \\
\hline $\mathrm{J}$ & 86 & 0.244 & 0.185 & 0.324 & 0.210 \\
\hline $\mathrm{K}$ & 920 & 3.34 & 2.62 & 0.414 & 0.280 \\
\hline Total & 37,800 & 141.1 & 102.7 & 0.426 & 0.266 \\
\hline
\end{tabular}

We see the six-year averages of the demand and capacity factors in Tables 1 and 2 respectively, however these quantities have clear seasonal patterns. Both parameters, but especially the wind resource, have significant year-to-year variation for a given month, indicated by the difference between the upper and lower bounds. These are shown in Fig. 5. 


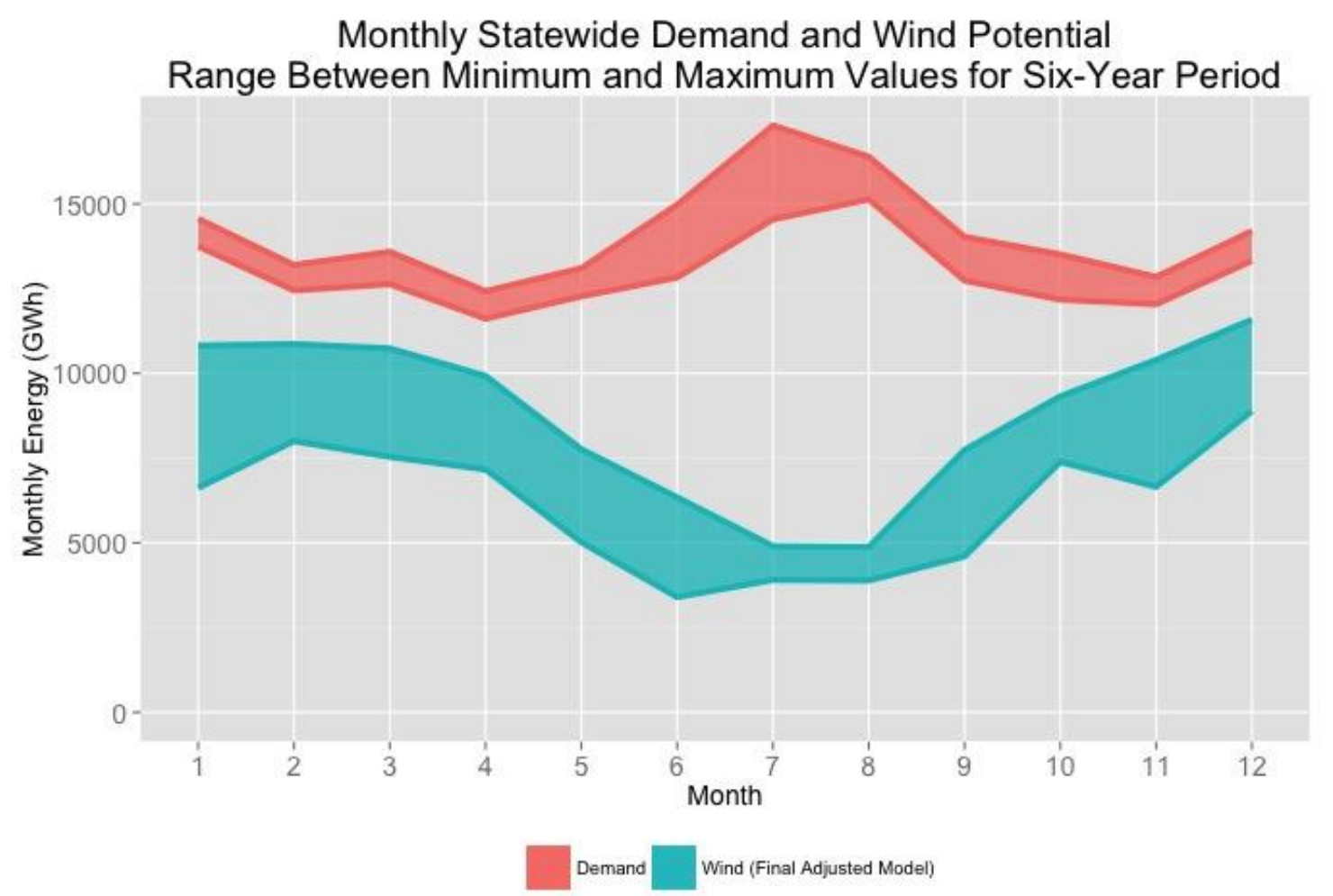

Fig. 5. Ranges of potential wind energy supply and electricity demand for each month in the sixyear data period. "Ribbons" are bound by the minimum and maximum monthly values for each parameter.

\section{Wind power capacity expansion analysis}

To analyze the impact of increasingly higher wind generation capacity in the State, while ensuring existing (and potentially new) grid constraints, the potential output from wind for the six years, 2007-12, is used in conjunction with actual demand for the same six years. We assume that both wind and demand are prescribed in our analysis and hence curtailment due to forecasting, scheduling and dispatch are not considered. When we consider installed wind capacities smaller than the maximum possible capacity according to NREL data, we select locations that represent the highest uncurtailed generation.

In carrying out this expansion analysis we evaluate the following performance metrics:

- net load requirements from sources other than wind and baseload generators;

- flow of wind-generated electricity between zones and expected transmission bottlenecks; we also evaluate the impact of alleviating those power flow disruptions;

- times of year when potential wind-generated electricity must be curtailed.

In order to evaluate the influence of various topographical characteristics of the system on these particular metrics, we used a process that progressively introduces constraints to the 
analysis. The flow chart in Fig. 6 shows this process, which is described in detail in the following subsections.

\begin{tabular}{|c|c|c|c|c|}
\hline $\begin{array}{c}\text { Wind Power } \\
\text { Model }\end{array}$ & $\begin{array}{l}\text { Uncurtailed } \\
\text { Wind Power }\end{array}$ & $\begin{array}{l}\text { Demand } \\
\text { Constraint }\end{array}$ & $\begin{array}{l}\text { Base Load } \\
\text { Generation }\end{array}$ & $\begin{array}{l}\text { Transmission } \\
\text { Limits }\end{array}$ \\
\hline $\begin{array}{l}\text { Wind power } \\
\text { output of } \\
\text { individual sites as } \\
\text { 5-minute time } \\
\text { series } \\
\text { (Section 3) }\end{array}$ & $\begin{array}{l}\text { Wind sites sorted } \\
\text { in order of } \\
\text { decreasing } \\
\text { uncurtailed } \\
\text { capacity factor } \\
\text { (Section 4.1) }\end{array}$ & $\begin{array}{l}\text { Potential wind- } \\
\text { generated } \\
\text { electricity } \\
\text { curtailed if no } \\
\text { demand } \\
\text { (Section } 4.2 \text { ) }\end{array}$ & $\begin{array}{l}\text { Base load } \\
\text { generation } \\
\text { cannot be } \\
\text { reduced to } \\
\text { accommodate } \\
\text { wind-generated } \\
\text { electricity } \\
\text { (Section 4.3) }\end{array}$ & $\begin{array}{l}\text { Linear program } \\
\text { model to } \\
\text { simulate power } \\
\text { flow to zonal } \\
\text { demands from } \\
\text { zonal supply } \\
\text { (Section 4.4) }\end{array}$ \\
\hline
\end{tabular}

Fig. 6. Flow chart of model development

\subsection{Uncurtailed wind-generated electricity}

The potential wind power sites identified for the NREL model were sorted in order of decreasing site uncurtailed $\mathrm{CF}, C F_{u, s}$. For a given total systemwide wind capacity, cap, the selected sites, $s$, are in the set, $S_{\text {cap }} . C_{\text {wind, } i}$ is the installed wind capacity at each site, with the maximum capacity at each site given by the NREL data set. $C F_{u, s}$ is computed from the wind power output, $W_{s, t}$, for each site at each time step, $t$, based on the six-year data set of 631,296 time steps, $\mathrm{T}$ :

$$
C F_{u, s}=\frac{\sum_{t=1}^{\mathrm{T}} W_{s, t}}{\mathrm{~T} C_{\text {wind }, s}}
$$

The sites considered within the selected set, $S_{c a p}$, are those that maximize the systemwide uncurtailed capacity factor $C F_{u, c a p}$ :

$$
C F_{u, c a p}=\frac{\sum_{t=1}^{\mathrm{T}} \sum_{s \in S_{\text {cap }}} W_{s, t}}{\mathrm{~T} \sum_{s \in S_{\text {cap }}} C_{\text {wind }, s}}
$$

\subsection{Demand constraint}

The NYISO demand data (Section 2.2) was used to apply the following constraint: Windgenerated electricity must be curtailed if there is no demand at that time step to which it could be applied. $D_{z, t}$ is the demand in zone, $z$, at time, $t$, where the total number of zones is $Z=11$. Therefore, for each systemwide wind capacity, cap, at each time step, $t$, the windgenerated electricity utilized for the demand-constrained case, $U_{d e m, c a p, t}$, is given by: 


$$
U_{\text {dem }, \text { cap }, t}=\min \left\{\sum_{s \in S_{c a p}} W_{s, t}, \quad \sum_{z=1}^{Z} D_{z, t}\right\}
$$

The wind power $\mathrm{CF}$ for the demand-constrained case, $C F_{d e m}$, can then be calculated for each total rated wind capacity:

$$
C F_{\text {dem,cap }}=\frac{\sum_{t=1}^{\mathrm{T}} U_{\text {dem }, \text { cap }, t}}{\mathrm{~T} \sum_{s \in S_{\text {cap }}} C_{\text {wind }, s}}
$$

\subsection{Baseload generation constraint}

This study is primarily interested in the utilization of potential wind-generated electricity and, subsequently, how the balance of the electricity supply system would respond to deeper penetration of wind power. However, since baseload generation may remain that cannot be varied or curtailed while remaining technically or economically viable $[47,48]$, we assume continuously operating nuclear power (i.e. without forced outages) of $532 \mathrm{MW}$ in Zone B and $1740 \mathrm{MW}$ in Zone C as baseload generation in the State. These capacities, when continuously operated would contribute, 4.6 TWh and 15.2 TWh, respectively, the values for actual 2014 electricity generation from those generators [47]. The nuclear baseload excludes one plant in Zone $\mathrm{C}$ that is slated to close in January 2017 and one plant in Zone $\mathrm{H}$ that the State government wants to close. Baseload generation also includes a monthly constant hydroelectric power output in each zone, computed by dividing the actual monthly electricity produced in each zone [38] by the number of hours in the respective month. A constant $1000 \mathrm{MW}$ hydroelectric baseload is also included for Zone J, in anticipation of an approved transmission project directly from Hydro Quebec to New York City [49]. ${ }^{2}$ Hydroelectric power is included as baseload generation to avoid curtailing existing low-to-no GHG emission resources.

The baseload generation in each zone at each time step, $B_{z, t}$, is then computed from the nuclear baseload generation in each zone, $B_{n u c, z}$, the actual electricity generated from hydro, $E_{\text {hydro,z,m(t) }}$, in each zone in the month, $m(t)$, corresponding to time, $t$, the number of hours in that month, $n_{h r s, m(t)}$, and the imposed constant hydroelectric baseload in each zone,

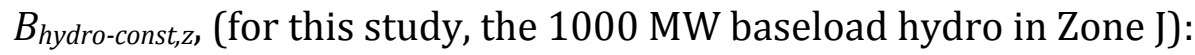

$$
B_{z, t}=B_{n u c, z}+B_{h y d r o-c o n s t, z}+\frac{E_{h y d r o, z, m(t)}}{n_{h r s, m(t)}}
$$

\footnotetext{
2 The baseload generation assumptions do not reflect any political opinion of the authors but represent a reasonable future baseload generation scenario given current trends in the State.
} 
The constraint that the baseload generation cannot be curtailed to allow wind-generated electricity to be utilized is applied for Statewide calculations at each time step to determine the wind-generated electricity utilized for the demand- and baseload generatorconstrained case, $U_{\text {dem.base,cap }, \text { : }}$

$$
U_{\text {dem.base,cap }, t}=\min \left\{\sum_{s \in S_{c a p}} W_{s, t}, \quad \sum_{z=1}^{Z} D_{z, t}-B_{z, t}\right\}
$$

The wind power $\mathrm{CF}$ for the demand- and baseload-constrained case, $C F_{\text {dem.base, }}$, can then be calculated for each total rated wind capacity:

$$
C F_{\text {dem.base }, \text { cap }}=\frac{\sum_{t=1}^{\mathrm{T}} U_{\text {dem.base }, \text { cap }, t}}{\mathrm{~T} \sum_{s \in S_{\text {cap }}} C_{\text {wind }, s}}
$$

\subsection{Transmission constraints - Linear program formulation}

The Statewide energy balance with expanded wind power penetration is constrained by the zonal distribution of electricity demands, wind power and baseload generation, and the transmission constraints between load zones.

For each zone, $z$, at each time step, $t$, the net load, $N L_{z, t}$, is given by:

$$
N L_{z}=\sum_{z=1}^{Z} D_{z, t}-U_{c a p, z, t}-B_{z, t}+T_{z z^{\prime}, t}-\left(1-l_{z z^{\prime}}\right) T_{z^{\prime} z, t}
$$

where $U_{z, t}$ is zonal wind-generated electricity utilized, $B_{z, t}$ is zonal baseload-generated electricity, $T_{z^{\prime} z, t}$ is electricity transmitted into the zone from another zone $z^{\prime}$ (including a loss factor, $l_{z z^{\prime}}$ ), and $T_{z z^{\prime}, t}$ is electricity transmitted out of the zone to another zone $z^{\prime}$. A single fixed loss factor $l_{z z^{\prime}}$, is applied to energy transmitted between any two zones. While $l_{z z^{\prime}}$ is not the precise transmission loss (which would vary with actual conductor sizes and transmission line load factors), a relatively high loss factor of 5\% per 100 miles was assumed to ensure that wind-generated electricity is first used close to its source. The average losses for a $345 \mathrm{kV}$ transmission line have been estimated as $4.2 \%$ per 100 miles [50], which does not include transformer losses; $345 \mathrm{kV}$ lines are most prevalent for long distance transmission in the State. Each transmission interface is modeled as a single line the distance "as the crow flies" between geographic centers of each zone; the loss factor for each transmission interface are shown in Appendix Table A5. The maximum total transmission losses from the simulations (the $37.5 \mathrm{GW}$ wind capacity scenario) were $3.27 \%$ whereas the average actual State losses were $3.18 \%$ according to a recent study [51], so the assumptions made here appear reasonable. 
In this paper we do not model principles of economic dispatch. Nor do we model the hundreds of individual generators, solar PV generation or out-of-state energy imports. The broad objective of the paper is to examine deep penetration of wind given the existing State grid and given the expectation of some amount of baseload generation that will not be curtailed in the future. For deep penetration of wind to occur affordably, it would be best to take advantage of hydropower's flexibility as a dispatchable resource used, if possible, when wind and nuclear together are unable to meet the full demand; however, there are constraints and complexities to this approach that are the subject of current research by others. For example, the available energy at a given time depends on the amount of water in the reservoir and the potential power output is limited by the height of that water relative to the river. These water reservoir characteristics are, in turn, dependent on weather and stream flow effects. Modeling the operation of hydroelectric generators warrants further study, but is beyond the scope of this study.

All net load - the remaining demand after utilizing the available wind, nuclear and hydro electricity - is most likely to be met by fossil fuel generators, whose use we wish to minimize for a given wind scenario. To this intent, the mathematical model developed for this analysis minimizes the Statewide net load (i.e. the sum of the zonal net loads) through the following objective function for each time, $t$ :

$$
\min \sum_{z=1}^{Z} N L_{z, t}, \forall t \in T
$$

subject to the following constraints for a given total installed wind capacity, cap:

$$
\begin{gathered}
U_{c a p, z, t} \leq \sum_{s \in\left\{S_{c a p}, S_{z}\right\}} W_{s, t}, \forall z \in Z, \forall t \in T \\
T_{z z^{\prime}, t} \leq L_{z z^{\prime}}^{+}, \forall z \in Z, \forall z^{\prime} \in Z, \forall t \in T \\
T_{z z^{\prime}, t} \leq L_{z z^{\prime}}^{-}, \forall z \in Z, \forall z^{\prime} \in Z, \forall t \in T \\
N L_{z, t} \geq 0, \forall z \in Z, \forall t \in T
\end{gathered}
$$

where $L_{z z \prime}^{+}$is the positive flow transmission limit on line $z-z^{\prime}$, and $L_{z z}^{-}$is the reverse flow transmission limit on line $z-z^{\prime}$. For most $z-z^{\prime}$, the transmission limits are zero in both directions because no transmission lines exist in the existing grid, primarily because the zones are not adjacent. The transmission limits for each line were assumed to be the same 
as the maximum limits designated by NYISO for the year 2016 network topology scenario in a recent system reliability study [33].

Following initial analyses using the model described in Eqs. (25-29), some exceptions to the NYISO transmission limits were made: Flows on the $G-H, H-I$ and $I-J$ were constrained to positive flow-only. Otherwise, the linear program occasionally selected a reverse flow condition on these lines. This is highly unlikely given the authors' understanding of the NYISO grid operation and the nature of the supply and demand in these areas, which directs electricity flow towards the demand centers of NYC and Long Island. Appendix Table A6 summarizes the final transmission line limits used in the analysis.

The above minimization problem with constraints is formulated as a Linear Program (LP) and solved using the "limSolve" package [52] in R [45]. The systemwide CF for each total installed wind capacity, cap, was calculated from the results of the linear program solved at each time step:

$$
C F_{c a p}=\frac{\sum_{t=1}^{\mathrm{T}} \sum_{z=1}^{Z} U_{c a p, z, t}}{\mathrm{~T} \sum_{s \in S_{c a p}} C_{w i n d, s}}
$$

After completing the analysis with baseload generation values from Table 3, the same analysis was performed with $B_{z, t}$ set to zero in Eq. (20). The wind-generated electricity utilized for the no-base-load scenarios was designated $U_{\text {dem.trans,cap; }}$ the systemwide wind power capacity factor for the no-base-load scenarios was designated $\mathrm{CF}_{\text {dem.trans,cap. }}$

\section{Results and interpretation}

The computed results are shown in the subsections below. We first establish the effect of corrections to the NREL wind power model and review existing site performance. We then compute systemwide capacity factors under various constraints at $500 \mathrm{MW}$ increments of Statewide wind power capacity between 0 and $37.5 \mathrm{GW}$. The following section presents the seasonal effects on curtailment and possible mitigation strategies. The last section details usage and congestion on individual transmission lines, as well as the effects of alleviating congestion on select lines.

\subsection{Effects of NREL model adjustments and existing site performance}

The predicted wind-generated electricity and associated supply-demand effects would be significantly higher without the process described in Section 3.1.4. This comparison is shown in Fig. 7, along with the actual and model performance of existing wind power sites in the State as of 2011 (1274 MW total), the year for which the wind power adjustment model was developed; "NREL Model" refers to the data directly from the NREL data set (Section 3.1.1) and the "Final Model" refers to the data set after the adjustments described in Section 3.1.4. 
The "NREL Model" and "Final Model" points indicate that suboptimal sites have been selected for wind power in the State to date; these points include the same high efficiency turbines modeled in developing the solid lines in the figure. The actual CF being lower than the adjusted model prediction is likely an indication that generally less efficient wind turbines have been used, which result in the approximately 0.25 systemwide CF. Had the NREL-assumed higher efficiency turbines been used at the same sites, a systemwide CF of approximately 0.30 is computed. Had optimal sites been selected for the given capacity and the higher efficiency turbines used, the solid "Final Model" line indicates a systemwide CF of 0.38 .

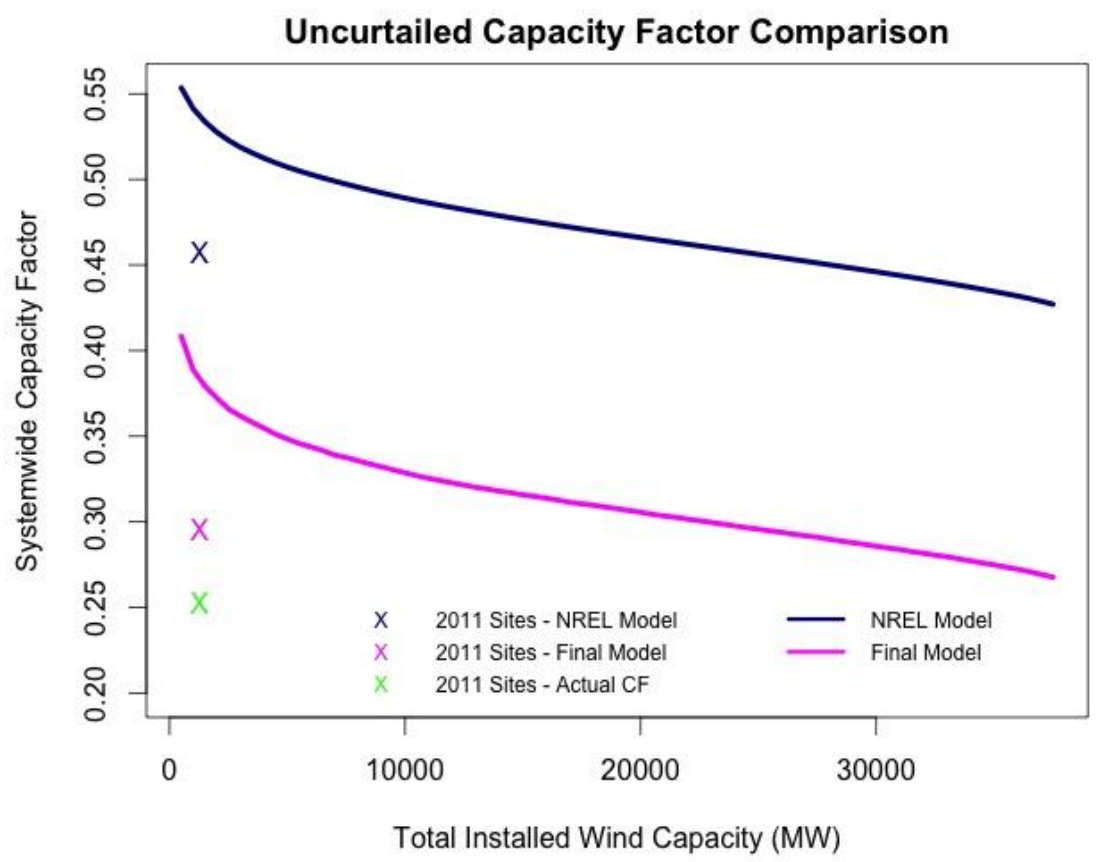

Fig. 7. Systemwide uncurtailed wind power capacity factor for various levels of total installed wind capacity. Compares NREL model (Section 3.1.1) to final adjusted model per Section 3.1.4. Also shown are capacity factors for the NREL model of existing (active 2011) wind sites, final adjusted model of existing wind site energy output and actual performance of existing wind sites in 2011.

Other factors not explicitly included in this modeling approach could also contribute to the lower-than-predicted CF; for example, site geography, wake effects from other turbines and forced outages. Some effect of site geography and wake effects are accounted for in the NREL model; however, the adjustment procedure described in Section 3.1.4 is purely data based and, thus, will capture the aggregate effects of these conditions on wind energy output. Outages are more difficult to identify given the available data.

\subsection{Systemwide capacity factors under constraints}

The constraint scenarios described in Section 2 and detailed in Section 4 do not begin to have an effect on wind power $\mathrm{CF}$, alone or in combination, until the total installed wind power capacity exceeds approximately $6 \mathrm{GW}$ when the continuous operation of baseload generators requires wind to be curtailed; without the baseload constraint, no wind is 


\section{Systemwide Wind Capacity Factor vs. Total Installed Wind Capacity}

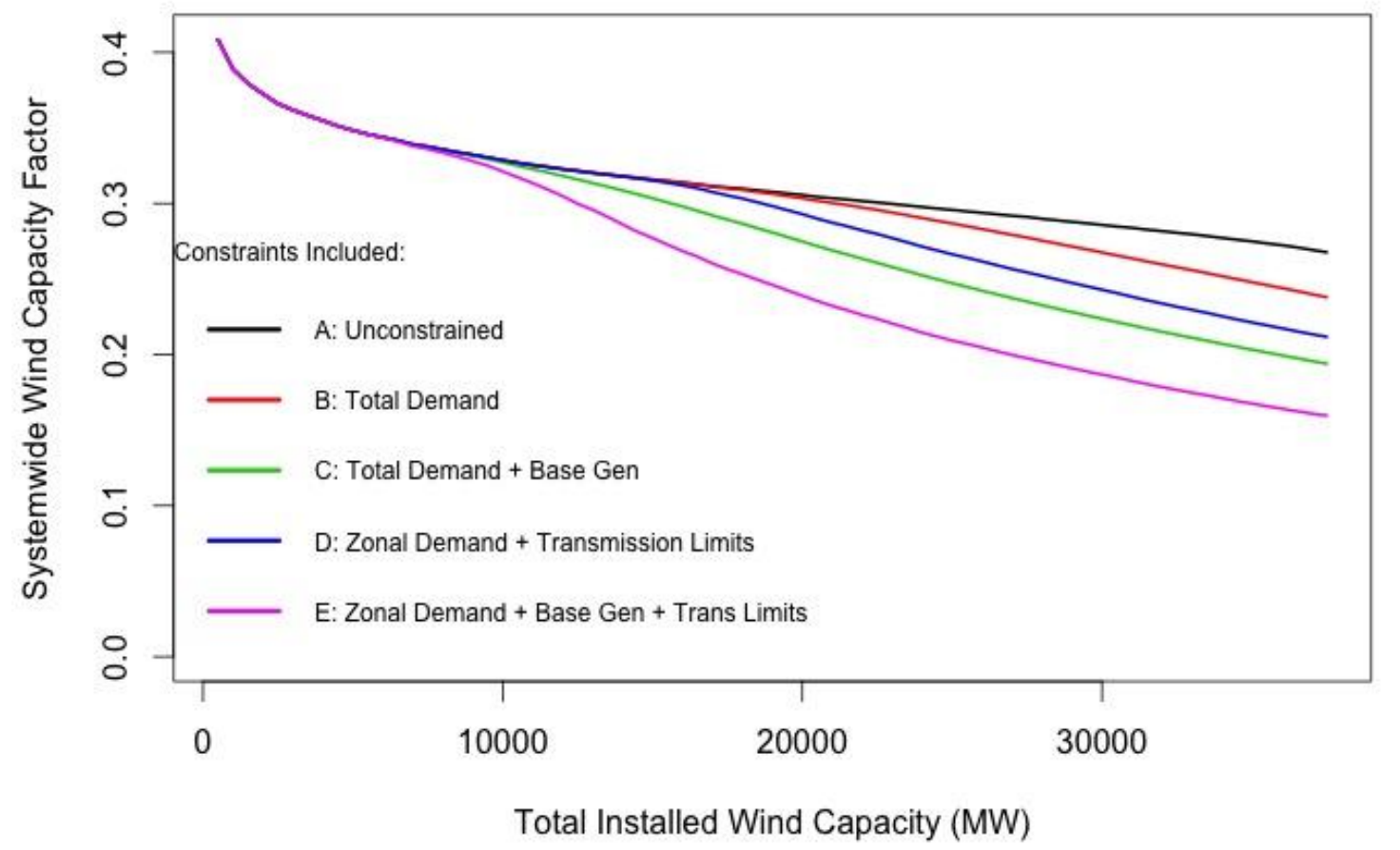

Fig. 8. Systemwide wind power capacity factor for various levels of total installed wind capacity under constraints: "Scenario A: Unconstrained" (Section 4.1); "Scenario B: Total Demand" Statewide wind-generated electricity utilization under Statewide demand constraint (Section 4.2); "Scenario C: Total Demand + Base Gen" - Statewide wind-generated electricity utilization under Statewide demand and baseload generation constraints (Section 4.3); "Scenario D: Zonal Demand + Transmission Limits" - Wind-generated electricity utilization with interzonal transmission limits and baseload generation set to zero for all zones (Section 4.4); "Scenario E: Zonal Demand + Base Gen + Trans Limits" - Wind-generated electricity utilization with interzonal transmission limits and baseload generation (Section 4.4)

At high penetration levels, the effects of the constraints begin to decrease the wind power CF. The misalignment of supply and demand (Scenario B), combined with the baseload generation constraint (Scenario C) are the primary contributors to curtailment at high wind capacities. In fact, the inclusion of baseload generation, which applies a constant reduction in load available to be met by wind-generated electricity, is a more significant contribution to the reduction in CF. The share of the curtailment caused by the Statewide demand profile increases as the wind power capacity increases. For example, at $20 \mathrm{GW}$ Statewide capacity, $0.7 \%$ of potential wind-generated electricity is curtailed due to the demand profile alone, whereas the addition of the baseload generation constraint requires 
an additional $9.4 \%$ of curtailment. The corresponding values at $30 \mathrm{GW}$ capacity are $6.4 \%$ and $15 \%$.

Introducing interzonal transmission limits and accounting for the zonal distribution of generation and demand (Scenario E) further increases curtailment; however, these effects are less significant. Under the same 20 and $30 \mathrm{GW}$ scenarios in the paragraph above, introducing the geographic effects adds, respectively, $11.7 \%$ and $12.9 \%$ curtailment.

The systemwide $\mathrm{CF}$ with all constraints included does not drop below the existing wind power CF of approximately 0.24 until $20 \mathrm{GW}$ total wind power capacity; however, it is not a perfect comparison as the wind turbines assumed in this analysis are likely to have higher capital costs than turbines that would perform similar to those at existing sites.

It can be useful to review the effects of curtailment from an economic perspective. The average cost per unit wind-generated electricity was calculated using the CFs discussed above and financing assumptions consistent with the EIA's Annual Energy Outlook [53]: overnight capital cost of wind power as $\$ 1980 / \mathrm{kW}$, a location adjustment multiplier of 1.01 for wind power in New York State, a 6.1\% annuitization rate for capital costs, and $\$ 39.53 / \mathrm{kW}$-yr operation and maintenance. Table 4 contains the $\mathrm{CF}$ and calculated unit cost of electricity for each of the constraint scenarios at 5, 10, 20 and $30 \mathrm{GW}$ total systemwide wind power capacity.

Table 4 - Wind capacity factor and electricity unit cost under various scenarios

\begin{tabular}{|l|c|c|c|c|}
\hline \multirow{2}{*}{ Scenario } & \multicolumn{4}{c|}{ CF $\{$ unit cost in \$/MWh $/$} \\
\cline { 2 - 5 } & $5 \mathrm{GW}$ Wind & $10 \mathrm{GW}$ Wind & $20 \mathrm{GW}$ Wind & $30 \mathrm{GW}$ Wind \\
\hline A: Unconstrained & $0.35\{53\}$ & $0.33\{56\}$ & $0.31\{60\}$ & $0.29\{65\}$ \\
\hline B: Demand Constraint & $0.35\{53\}$ & $0.33\{56\}$ & $0.30\{61\}$ & $0.27\{69\}$ \\
\hline $\begin{array}{l}\text { C: Demand Constraint + } \\
\text { Baseload Generation }\end{array}$ & $0.35\{53\}$ & $0.33\{56\}$ & $0.27\{67\}$ & $0.22\{82\}$ \\
\hline $\begin{array}{l}\text { D: Zonal Demand + } \\
\text { Transmission Limits }\end{array}$ & $0.35\{53\}$ & $0.33\{56\}$ & $0.29\{63\}$ & $0.24\{72\}$ \\
\hline $\begin{array}{l}\text { E: Zonal Demand + Base Gen. + } \\
\text { Trans. Limits }\end{array}$ & $0.35\{53\}$ & $0.32\{57\}$ & $0.24\{77\}$ & $0.19\{99\}$ \\
\hline
\end{tabular}

Under the $20 \mathrm{GW}$ scenario, the difference in average unit cost of wind-generated electricity begins to differentiate depending on the constraints; however, at $30 \mathrm{GW}$ total wind power capacity, the various constraints have more influence over the energy cost with a $50 \%$ increase in cost between the unconstrained case and Scenario E. Given that at $10 \mathrm{GW}$ there is minimal difference in the model-predicted CFs and costs, these results indicate the possibility of a gradual transition to very deep wind power penetration accommodated by different supply, demand and adaptation measures happening concurrently. 


\subsection{Wind curtailment effects of imposing constraints}

Scenario B considered the hypothetical case where the only constraint curtailing wind was the statewide demand. This would lead to remaining baseload generation being ramped up and down and/or curtailed (typically an expensive or infeasible operational situation for many baseload plants). How wind and such baseload plants would be curtailed is illustrated in Fig. 9 using monthly energy data for the six-year period. For $20 \mathrm{GW}$ of wind, baseload energy curtailments would be $9.2 \%$ (Fig. 9a), whereas for the $30 \mathrm{GW}$ case (Fig. $9 \mathrm{~b}$ ) the curtailment increases to $21 \%$. These results clearly show that significant curtailments occur primarily in the winter months.
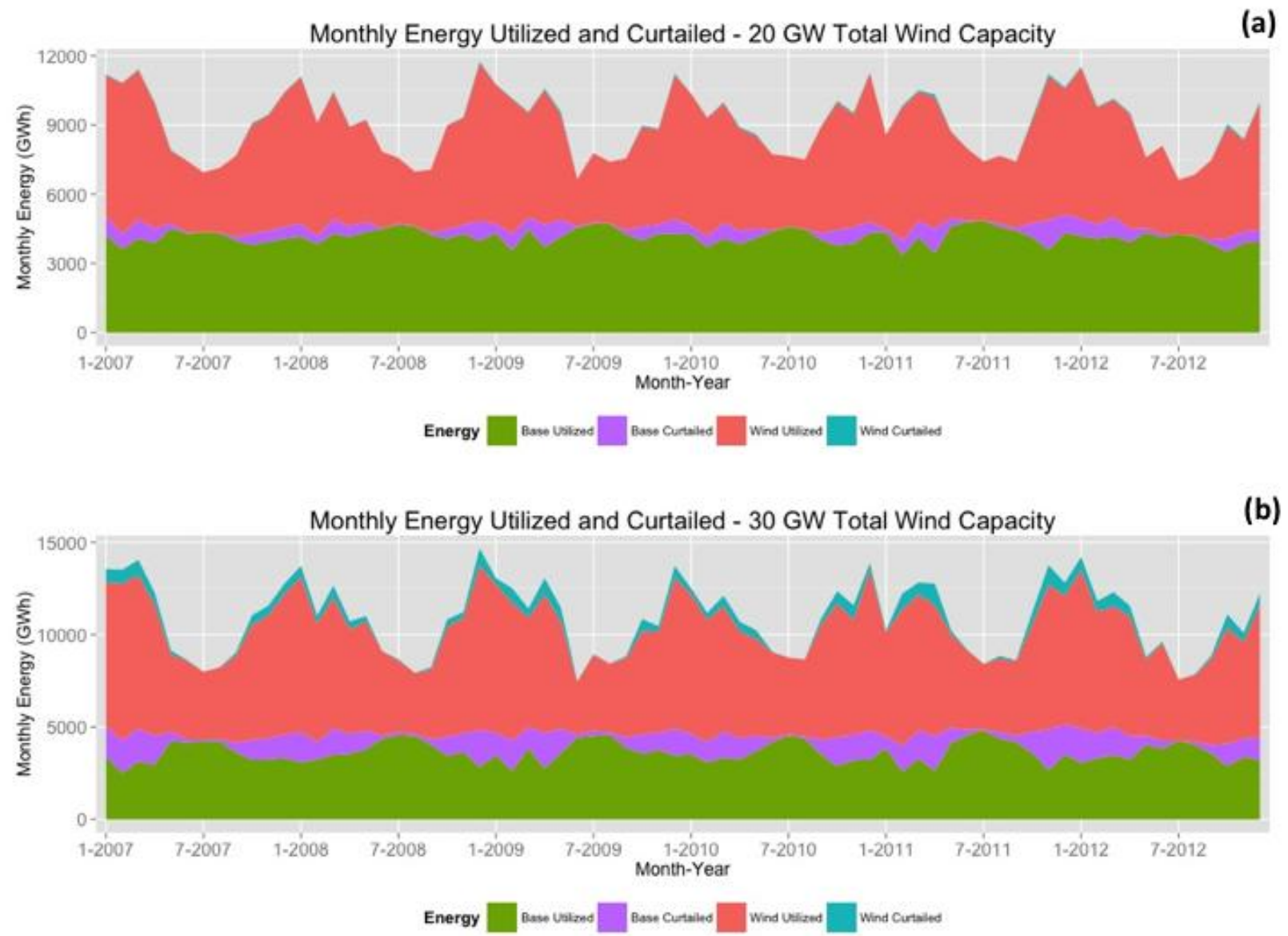

Fig. 9. Monthly wind- and baseload plant-generated electricity utilization and curtailment with Statewide demand constraint (Scenario B, Section 4.2) for (a) 20 GW and (b) 30 GW scenarios. Figures show the monthly baseload generation that would need to be curtailed to allow maximum wind utilization.

Since the figures show monthly energy curtailments, they mask the deep potential power curtailments. For the $20 \mathrm{GW}$ (and $30 \mathrm{GW}$ case) case the power curtailments at times would be so high as to require the entire baseload fleet to be curtailed $2.6 \%$ of the year, on average, and increasing to $13.1 \%$ of the time for the $30 \mathrm{GW}$ scenario. 
Scenario B is illustrative but clearly shows the value of Scenario C, that ensures that curtailing baseload generation is not permitted. The results of Scenario C, shown in Fig. 10 (where baseload is not shown in the figure), show that by operating baseload continuously, wind generation curtailment is significantly higher in the winter months with additional curtailments in other months. Hydropower is slightly higher in some winter months; however this only exacerbates this effect, which is driven by the higher wind during this time period and the generally high year-round baseload generation.
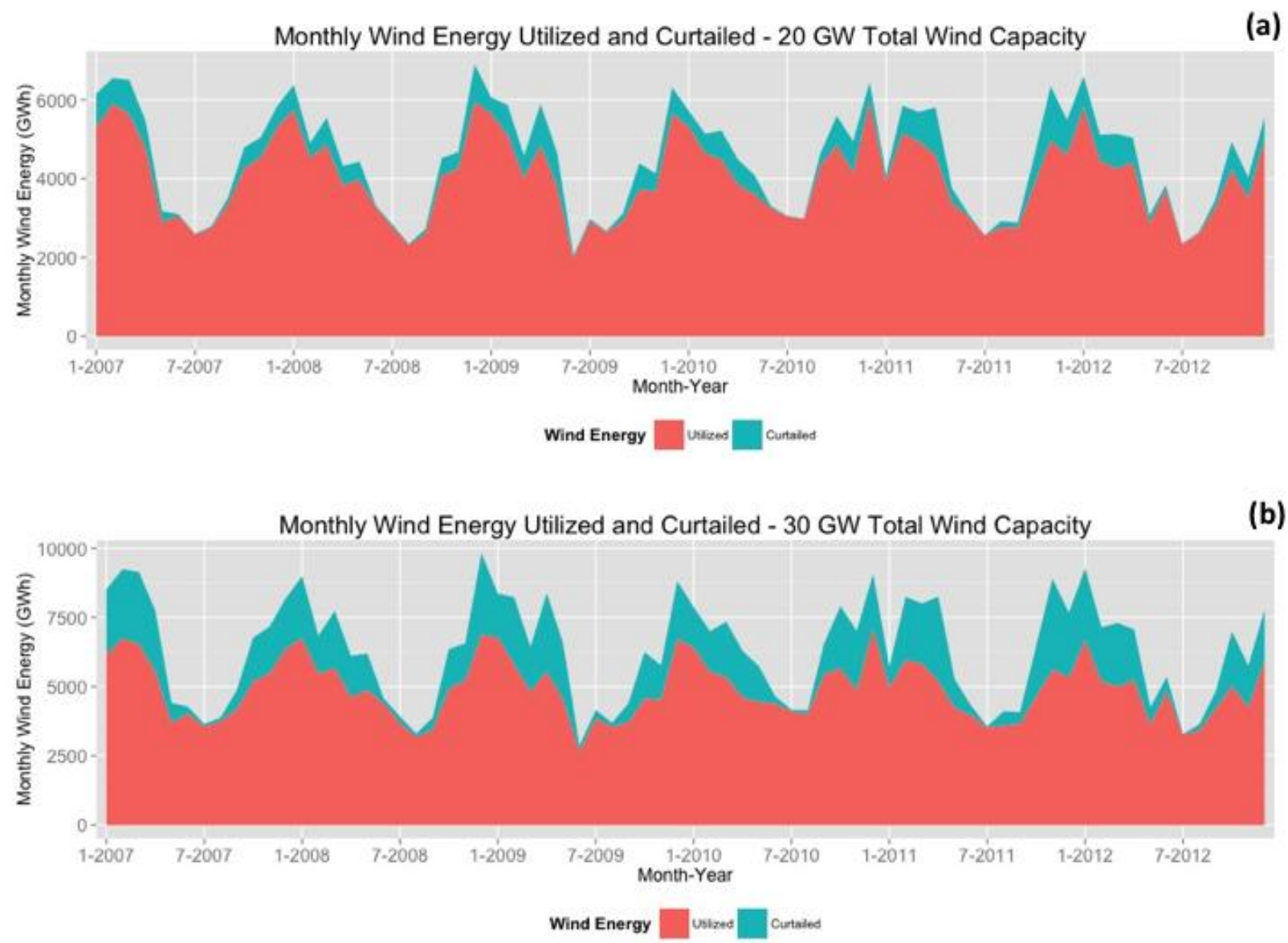

Fig. 10. Monthly wind-generated electricity utilization and curtailment with Statewide demand and baseload generation constraints (Scenario C, Section 4.3) for (a) 20 GW and (b) 30 GW scenarios

Monthly energy curtailments after introducing the additional constraint of interzonal transmission limits and geographical distribution of generation and demand (i.e. Scenario E) are shown in Fig. 11 where the differences from Scenario $C$ are highlighted. Once transmission limits are imposed, the location of wind supply and electricity demand also start to matter; however, these figures show the transmission limits do not appear to significantly alter the nature of curtailment but primarily exacerbate the winter-time curtailment when wind generation is highest. Excess winter-month generation is aligned with the idea that fossil fuel-based space heating boilers might increasingly be replaced by electric heat pumps. Such a shift would allow lower space heating-related emissions and lower wind curtailments. 

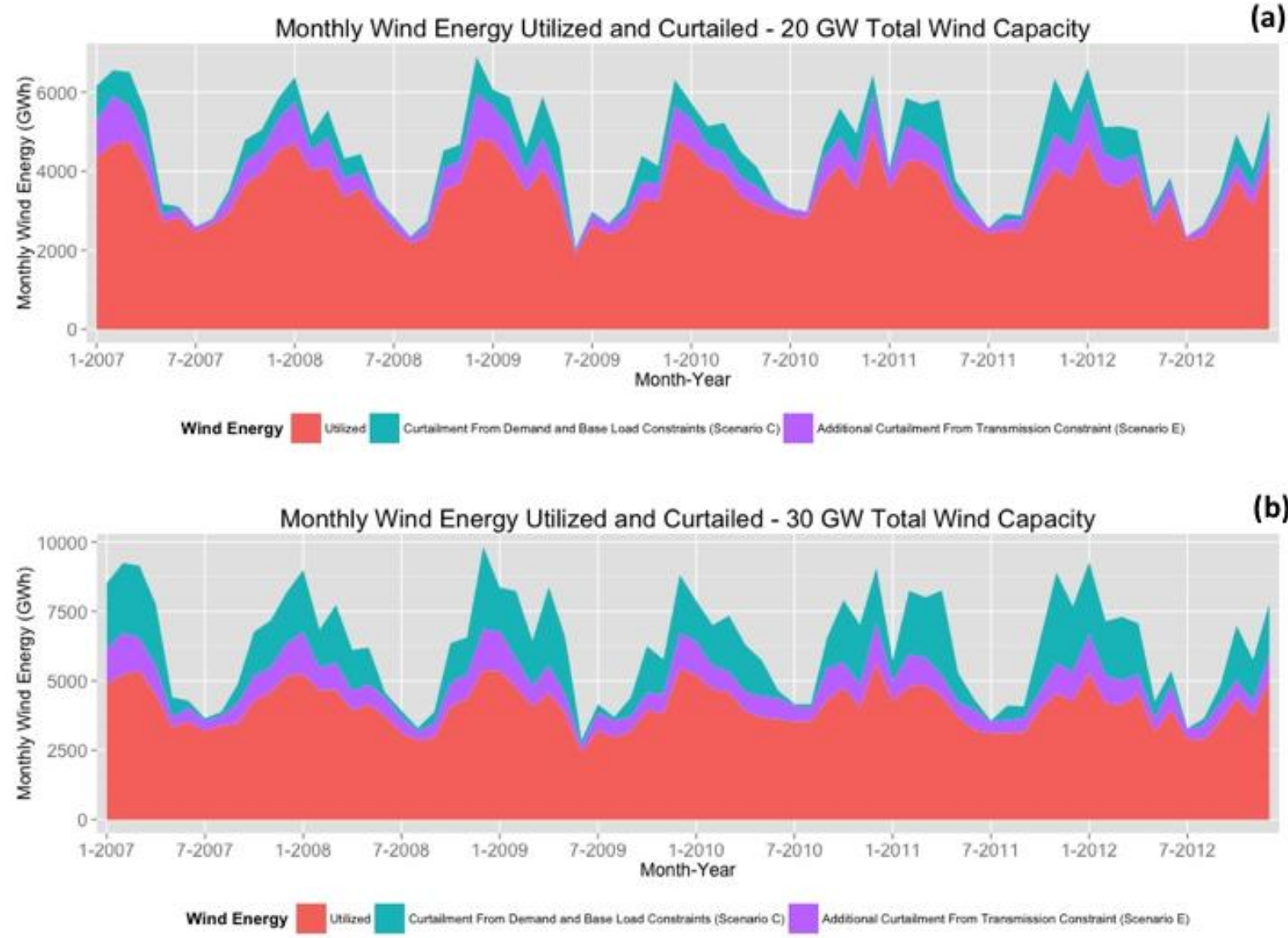

Fig. 11. Monthly wind-generated electricity utilization and curtailment with linear program power flow model, including zonal wind-generated electricity, demand and baseload generation, as well as interzonal transmission constraints (Scenario E, Section 4.4) for (a) $20 \mathrm{GW}$ and (b) $30 \mathrm{GW}$ scenarios. Differences in monthly curtailment between Scenarios E and C are highlighted to show the effect of adding the transmission constraint to the demand- and baseload-constrained model.

When considering all constraints (Scenario E), 22\% of the total potential wind-generated electricity in the $20 \mathrm{GW}$ case is curtailed in the six-year model (35\% in the $30 \mathrm{GW}$ case). Regardless of the constraints considered, wind curtailment is primarily a winter issue due both to the higher potential wind-generated electricity in the winter and the higher electricity demand in the summer (a relationship first shown above in Fig. 5). For the 20 GW model, $70 \%$ of all curtailment occurs between October and March (68\% for the $30 \mathrm{GW}$ case).

\subsection{Transmission bottlenecks and relief}

The most constrained transmission path (i.e. set of transmission lines between nonadjacent zones) is that which allows electricity to flow from Zone E, through Zone G, to Zone J; that is, the transmission of wind-generated electricity from the northern and western parts of the State to the highly concentrated southeastern electricity demand in 
NYC. The other highly loaded transmission lines constitute an alternate path for this same electricity along the route E-F-G-H-I-J. The transmission interfaces at which the flow constraints have the largest impact on power flow can be seen in the heat maps shown in Fig. 12, which for select wind capacities show (a) the percentage of the time each line is at full capacity and (b) the capacity factor of each line over the six-year simulation period.

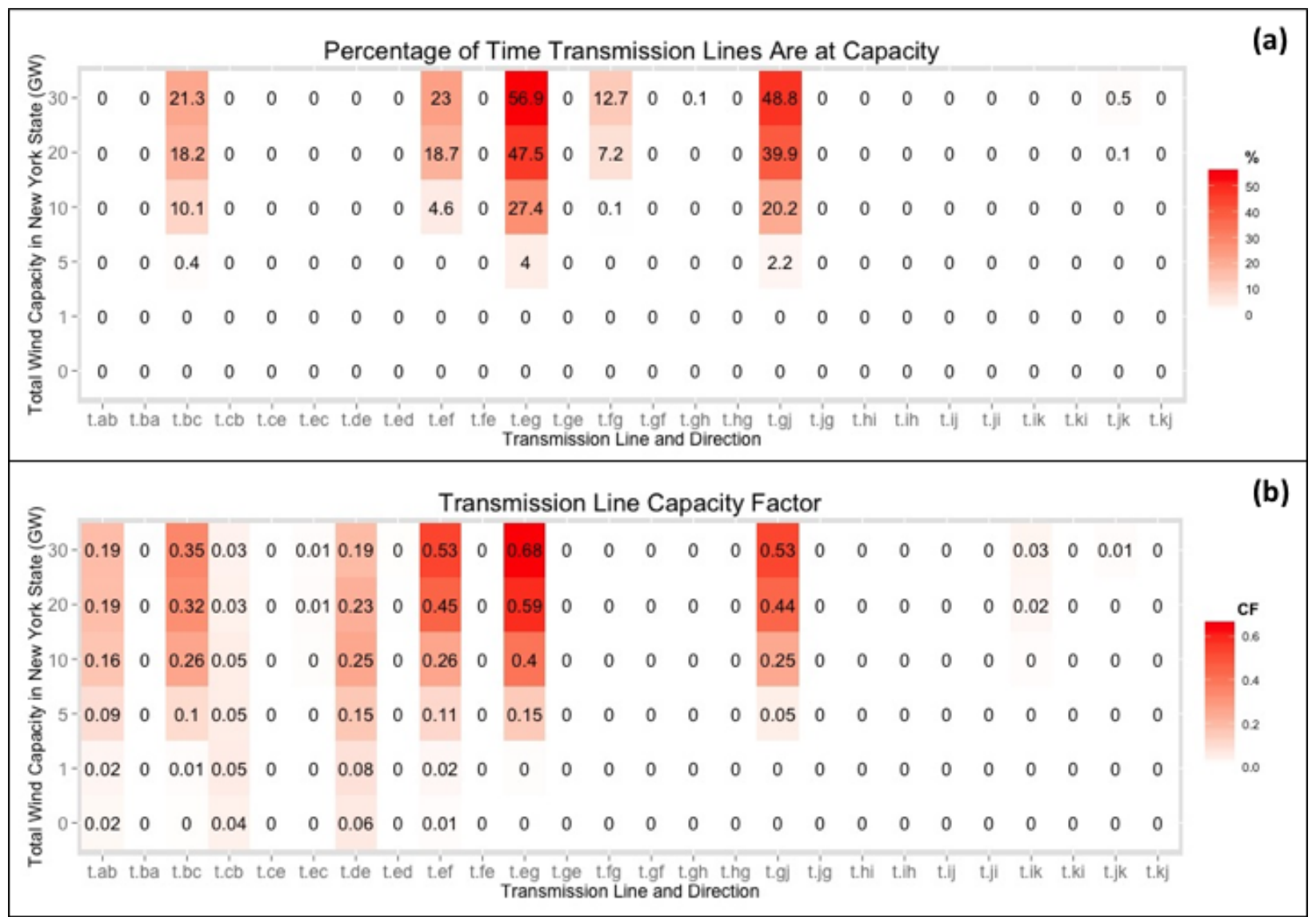

Fig. 12. Heat maps of (a) percentage of time transmission lines are at capacity and (b) transmission line capacity factor for discrete levels of total installed wind power capacity.

Allowing nearly infinite flow on $E-G$ and $G$-J relieves this bottleneck, increasing the systemwide wind power CF to very nearly the CF of the Statewide demand-and baseload generation-constrained cases (Scenario C). Nonetheless, the curtailment due to offset supply and demand profiles, constrained by baseload generation operation, remains an issue.

To capture the full benefits of eliminating congestion on these transmission lines would require more than doubling the total transmission line capacity between Zones $\mathrm{E}$ and J. In the $30 \mathrm{GW}$ scenario, reducing incidence of congestion from $57 \%$ of the time to $10 \%$ in the transmission link from Zone E to Zone J, would require an upgrade of capacity of $1912 \mathrm{MW}$ between Zone $\mathrm{E}$ and Zone $\mathrm{G}$ and an upgrade of $980 \mathrm{MW}$ between Zone $\mathrm{G}$ and Zone J. The 

reduction in curtailment would increase the wind CF from 0.186 to 0.204 . To provide context, this investment could be recovered over a 10 -year period if the additional electricity could be sold at a premium of 1.7 cents/kWh while increasing the windgenerated electricity utilized by $10 \%$.

A more in-depth evaluation of the potential benefit of future transmission upgrades would need to incorporate the effects of the location of any changes to the State's electricity demand profile, as significant increasing in transmission capacity may not be warranted if increases in winter demand occur closer to wind resources.

\section{Discussion}

This paper examines deep penetration of wind power in New York State through the lens of curtailment as a metric to examine possible broad-scope interventions. While no direct economic optimization is attempted, through the use of scenarios with and without existing zonal electricity demands; with and without uncurtailed baseload generation; and with and without existing and upgraded transmission limits, we are able to provide insight into how economic viability changes with massively deeper penetrations of wind in the State grid. The fact that we neglect the role of solar, that nuclear-based power is preserved as baseload and that hydropower is treated as baseload in our model does not reflect ideological choices. Instead, this framing keeps the problem specification manageable, allows one to examine the role of variable power vis-à-vis baseload and also lends the solutions to clearer interpretations.

The analysis indicates that a significant increase to as much as 6-10 GW of wind capacity is viable in New York State even in the absence of major demand-side, storage, transmissionupgrade or other market intervention measures. In fact, the study suggests that significant room for performance improvement of wind power exists simply through installations at optimal locations using efficient turbines. An a priori evaluation of wind performance combining NREL wind data with actual performance data using proposed models would be a valuable aid in both selecting sites and assessing how the site-specific generation fits into existing transmission network and demand patterns.

The variability and mismatch in time of potential wind-generated electricity supply with existing electricity demand can significantly reduce wind power capacity factor at high levels of installed capacity (particularly over $10 \mathrm{GW}$ ). Increasingly sharp curtailments of wind power would occur during the winter months, with installed capacities increasing to 20GW and 30GW. While some short time-scale demand shifts (e.g. diurnal profile changes) could be accommodated by energy storage or demand-side management technologies, the dominant effect is seasonal, and hence less economically viable using storage. As such, the integration of high efficiency electric heat pumps could both provide a demand for large

${ }^{3}$ Based on an assumed transmission cost of $\$ 2500$ per MW per mile (the average for a 345 $\mathrm{kV}$ double circuit line in [50]) an increases in capacity on the $E-G$ and $G-J$ lines of $1912 \mathrm{MW}$ and $980 \mathrm{MW}$, respectively. 
wind power capacities and improve the GHG emissions impact of space heating-typically reliant on on-site combustion of fossil fuels-as a previous study by the authors has shown [54].

Historically baseload generation has been either from coal or nuclear. In the last few years, as natural gas prices have dropped and efficiency has increased, the economics of combined cycle gas turbines (CCGT) have become favorable in the U.S. even as baseload, and hence, CCGT is gradually displacing coal. While not examined here, this shift would allow lower emissions as well as more flexibility to handle variable wind, but also may redefine baseload generation as not necessarily continuously-operating (or do away with that designation entirely). If nuclear baseload is entirely replaced with CCGT technology, while there are some benefits to wind integration they pale in comparison to much higher emissions; we do not comment here on the disadvantages of nuclear energy or arguments for its expansion, but it currently provides an inexpensive source of continuous electricity with minimal GHG emissions.

Hydroelectric power output was assumed to be constant at every time step within a given month, but the dispatchability of hydropower is likely to reduce wind curtailments below those computed with the baseload constraint in this paper. That said, hydropower's flexibility remains limited by seasonal stream flow effects, reservoir capacity and rated power capacity of a facility's turbines. The results of this study strongly support efforts to integrate hydro and wind resources to reduce curtailment and, thus, reduce net loads requiring electricity from fossil fuel-burning generators.

The study does identify a scenario that alleviates just a couple of the binding transmission bottlenecks: Predicted systemwide wind power CF rapidly improves, yet remains limited by the lack of adequate seasonal demand for the potential supply considering continuous baseload operation. While further study is required to investigate the complexities of these effects, some demand-side strategies may be particularly viable in geographic regions farther from the wind supply. For example, the likely lower heating demands per person and higher heat pump coefficient of performance (COP) in NYC compared to northern parts of the State may make it more attractive for replacement of existing space heating with heat pumps.

While geographical effects at specific sites beyond those accounted for in the NREL model and wake and turbulence effects within individual sites, are not explicitly modeled, the current methodology partially captures these effects through the power output adjustment based on measured wind turbine output data. Other considerations - such as grid operation affected by forecasting, market mechanisms, forced outages and improvements in technology over time, as well as improved viability of off-shore wind power - were not included in this study.

Although the six-year time period analyzed for this study represents a long-time-frame deterministic model, extreme weather events are not captured. Adequate balance-ofsystem capacity and the correct generator types will be required in the event that wind speeds drop precipitously or very high wind speeds cause turbines to "cut out" en masse 

of installed wind turbines, though the degree to which they do will depend on their frequency.

Accommodating wind power is also likely to require zonal measures that ensure reliability, including increases in reserve requirements and fast-ramping/regulation entities. The precise amount of distributed generation, where such generation is located and the duty cycle it would experience has not been studied here but needs to be examined. It is likely that distributed generators with low capacity factors may be significantly lower cost than centralized approaches to provide standby capacity.

\section{Conclusions}

We assess the implications of deep penetration of wind power into an existing regional grid using wind capacity factor as a metric. This is done by first ensuring that NREL wind data are adjusted to better match measurements. Second, a methodology for evaluating constraints on wind-generated electricity utilization that takes into account, demand, baseload and transmission is developed. We report the resulting impact on systemwide wind power capacity factors, seasonal curtailment patterns and identify transmission bottlenecks.

The wind power model indicates that existing wind power sites in New York State underperform due to suboptimal site selection and the use of relatively inefficient turbines.

Seasonal and diurnal mismatches in wind supply and demand coupled with continuously operating baseload generation have the most significant impact on the curtailment of windgenerated electricity. With deep wind penetration, approximately $70 \%$ of curtailment occurs from October to March, periods of high wind power and low to moderate electricity demand.

Interzonal transmission constraints further increase curtailment and the specific linkages that cause the bottlenecks are identified. Relieving every bottleneck is unlikely to be costeffective. We have identified linkages where more modest increases in transmission capacity (i.e. to allow $90 \%$ of potential electricity flows to the high-demand Southeast) can significantly reduce curtailment at very high wind power capacities.

The paper examines wind penetrations up to $37.5 \mathrm{GW}$ in capacity. An important conclusion of this study is that until 6-10 GW of installed wind capacity, up to five times the current installed wind capacity, we find no or minimal curtailment caused by any of the above constraint.

At larger penetrations as one transitions to a low-carbon grid, many other measures will be needed. Amongst these are: dispatchable distributed generation, upgraded transmission capacity, energy storage, demand response and adapting to increasingly electric transportation and heating loads. Forced outages, forecasting limitations and market operation are not modeled in this study. Significant advances by others in these fields will 
need to be integrated with the energy planning metrics explored here. The means by which net loads are met in a high wind power future is of particular interest to the authors. A forthcoming paper will address the generator mix to accommodate the variability of the large capacities of wind power anticipated in this study and the associated net load ramping effects.

\section{Acknowledgements}

The authors would like to thank the staff at NREL who assisted us in accessing the full wind model data set, in particular Dan Getman, Bri-Mathias Hodge and Paul Edwards; they were very helpful despite the possible testiness of an impatient graduate student. Partial support for this research was provided by the National Science Foundation (NSF) IGERT "Solving Urbanization Challenges by Design" (NSF Award Number 0903597) and the NSF SRN Award "Integrated Urban Infrastructure Solutions for Environmentally Sustainable, Healthy and Livable Cities" (NSF Award Number 1444745). 


\section{Appendix}
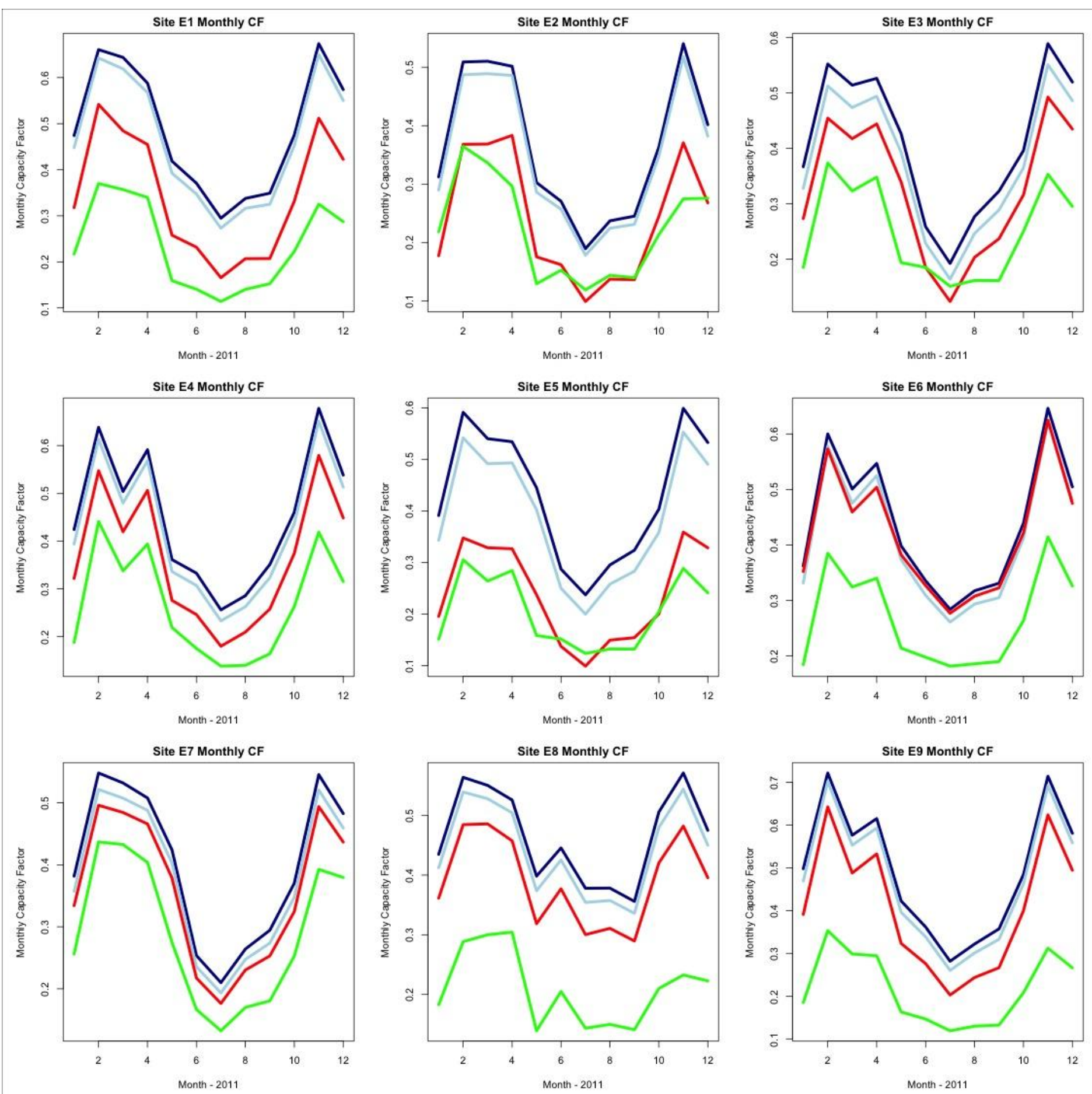

54

55

Fig. A1a. Monthly Capa city Factors of Existing Wind Power Sites - Sites E1-E9. Plot lines correspond to: Section 3.1.1 - NREL Model ("NREL"); Section 3.1.2 - NREL Hub Height-Adjusted Model ("NREL-Adj"); Section 3.1.3 - 


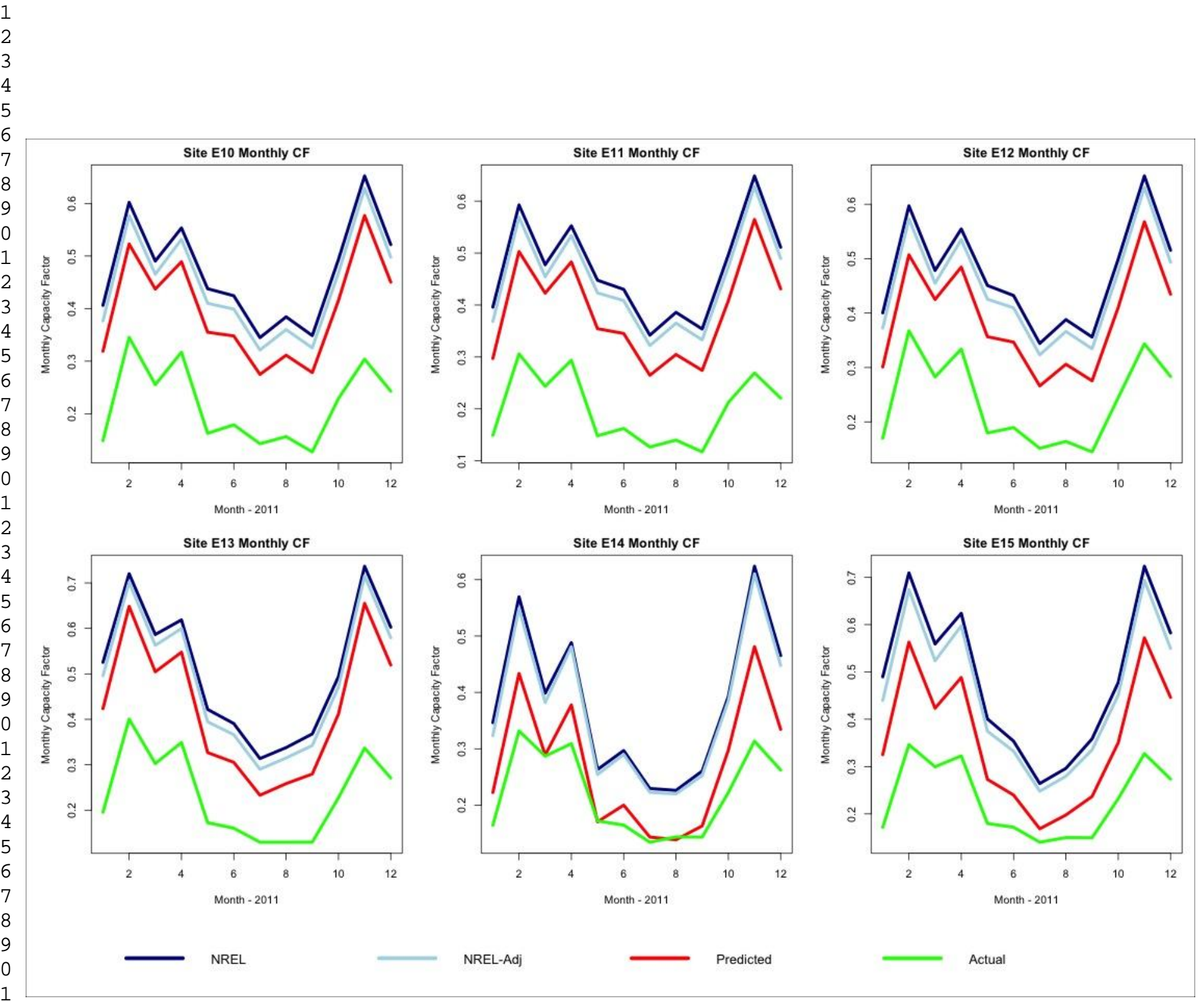


Table A1. Summary of Missing Values in NYISO 5-Minute Demand Data

\begin{tabular}{|c|c|}
\hline Zone & Missing Data Points \\
\hline A & 83 \\
\hline B & 84 \\
\hline C & 84 \\
\hline D & 81 \\
\hline E & 93 \\
\hline F & 82 \\
\hline G & 81 \\
\hline H & 85 \\
\hline I & 85 \\
\hline J & 83 \\
\hline K & 82 \\
\hline
\end{tabular}

Table A2. Summary of Relevant Existing Wind Power Site Information

\begin{tabular}{|c|c|c|c|}
\hline Site ID & Turbine ID & Hub Height $(\mathrm{m})[40]$ & IEC Class $^{1}$ \\
\hline E1 & T1 & 80 & 3 \\
\hline E2 & T1 & 80 & 2 \\
\hline E3 & T2 & 65 & 2 \\
\hline E4 & T3 & 80 & 3 \\
\hline E5 & T4 & 67 & 2 \\
\hline E6 & T5 & 80 & 2 \\
\hline E7 & T3 & 80 & 2 \\
\hline E8 & T3 & 80 & 3 \\
\hline E9 & T3 & 80 & 3 \\
\hline E10 & T3 & 80 & 3 \\
\hline E11 & T3 & 80 & 3 \\
\hline E12 & T3 & 80 & 3 \\
\hline E13 & T3 & 80 & 3 \\
\hline E14 & T6 & 85 & 2 \\
\hline E15 & T7 & 65 & 2 \\
\hline \multicolumn{2}{|l|}{1 Per the nearest NREL-identified site [55] } \\
\hline
\end{tabular}

Table A3. Power Curves of NREL Model Wind Turbines - Normalized by Turbine Capacity

\begin{tabular}{|c|c|c|c|}
\hline \multirow{2}{*}{$\begin{array}{c}\text { Wind Speed } \\
(\mathrm{m} / \mathrm{s})\end{array}$} & \multicolumn{3}{|c|}{ Normalized Power Output } \\
\cline { 2 - 4 } & IEC Class 1 & IEC Class 2 & IEC Class 3 \\
\hline 0 & 0 & 0 & 0 \\
\hline 1 & 0 & 0 & 0 \\
\hline 2 & 0 & 0 & 0 \\
\hline 3 & 0.0043 & 0.0052 & 0.0054 \\
\hline 4 & 0.0323 & 0.0423 & 0.053 \\
\hline
\end{tabular}




\begin{tabular}{|c|c|c|c|}
\hline 5 & 0.0771 & 0.1031 & 0.1351 \\
\hline 6 & 0.1426 & 0.1909 & 0.2508 \\
\hline 7 & 0.2329 & 0.3127 & 0.4033 \\
\hline 8 & 0.3528 & 0.4731 & 0.5952 \\
\hline 9 & 0.5024 & 0.6693 & 0.7849 \\
\hline 10 & 0.6732 & 0.8554 & 0.9178 \\
\hline 11 & 0.8287 & 0.9641 & 0.9796 \\
\hline 12 & 0.9264 & 0.9942 & 1 \\
\hline 13 & 0.9774 & 0.9994 & 1 \\
\hline 14 & 0.9946 & 1 & 1 \\
\hline 15 & 0.999 & 1 & 1 \\
\hline 16 & 0.9999 & 1 & 1 \\
\hline 17 & 1 & 1 & 1 \\
\hline 18 & 1 & 1 & 1 \\
\hline 19 & 1 & 1 & 1 \\
\hline 20 & 1 & 1 & 1 \\
\hline 21 & 1 & 1 & 1 \\
\hline 22 & 1 & 1 & 1 \\
\hline 23 & 1 & 1 & 0 \\
\hline 24 & 1 & 1 & 0 \\
\hline 25 & 1 & 1 & 0 \\
\hline 26 & 0 & 0 & 0 \\
\hline
\end{tabular}

Table A4. Power Curves of Existing Site Wind Turbines - Normalized by Turbine Capacity

\begin{tabular}{|c|c|c|c|c|c|c|c|}
\hline \multirow{2}{*}{$\begin{array}{c}\text { Wind Speed } \\
(\mathrm{m} / \mathrm{s})\end{array}$} & \multicolumn{7}{|c|}{ Normalized Power Output } \\
\cline { 2 - 8 } & $\mathrm{T} 1$ & $\mathrm{~T} 2$ & $\mathrm{~T} 3$ & $\mathrm{~T} 4$ & $\mathrm{~T} 5$ & $\mathrm{~T} 6$ & $\mathrm{~T} 7$ \\
\hline 0 & 0 & 0 & 0 & 0 & 0 & 0 & 0 \\
\hline 1 & 0 & 0 & 0 & 0 & 0 & 0 & 0 \\
\hline 2 & 0 & 0 & 0 & 0 & 0 & 0 & 0 \\
\hline 3 & 0 & 0 & 0 & 0 & 0 & 0 & 0 \\
\hline 4 & 0.0098 & 0.0060 & 0.0240 & 0.0305 & 0.0050 & 0.0045 & 0.0447 \\
\hline 5 & 0.0483 & 0.0386 & 0.0693 & 0.0858 & 0.0457 & 0.0405 & 0.1438 \\
\hline 6 & 0.1060 & 0.0925 & 0.1367 & 0.1672 & 0.1248 & 0.0873 & 0.2735 \\
\hline 7 & 0.1926 & 0.1694 & 0.2293 & 0.2845 & 0.2108 & 0.1512 & 0.4126 \\
\hline 8 & 0.3043 & 0.2657 & 0.3520 & 0.4377 & 0.3358 & 0.2353 & 0.5588 \\
\hline 9 & 0.4520 & 0.3948 & 0.5160 & 0.6267 & 0.4677 & 0.3393 & 0.7030 \\
\hline 10 & 0.6360 & 0.5520 & 0.7193 & 0.7933 & 0.6088 & 0.4532 & 0.8242 \\
\hline 11 & 0.8080 & 0.7360 & 0.8947 & 0.9133 & 0.7407 & 0.5659 & 0.9091 \\
\hline 12 & 0.9280 & 0.8640 & 0.9733 & 0.9600 & 0.8427 & 0.6713 & 0.9576 \\
\hline 13 & 0.9800 & 0.9520 & 0.9960 & 0.9867 & 0.9195 & 0.7688 & 0.9879 \\
\hline 14 & 1 & 0.9920 & 1 & 1 & 0.9733 & 0.8570 & 1 \\
\hline 15 & 1 & 1 & 1 & 1 & 1 & 0.9270 & 1 \\
\hline
\end{tabular}




\begin{tabular}{|l|l|l|l|l|l|l|l|}
\hline 16 & 1 & 1 & 1 & 1 & 1 & 0.9712 & 1 \\
\hline 17 & 1 & 1 & 1 & 1 & 1 & 0.9915 & 1 \\
\hline 18 & 1 & 1 & 1 & 1 & 1 & 0.9976 & 1 \\
\hline 19 & 1 & 1 & 1 & 1 & 1 & 1 & 1 \\
\hline 20 & 1 & 1 & 1 & 1 & 1 & 1 & 1 \\
\hline 21 & 1 & 1 & 1 & 1 & 1 & 1 & 0 \\
\hline 22 & 1 & 1 & 1 & 1 & 1 & 1 & 0 \\
\hline 23 & 1 & 1 & 1 & 1 & 1 & 1 & 0 \\
\hline 24 & 1 & 1 & 1 & 1 & 1 & 1 & 0 \\
\hline 25 & 1 & 1 & 1 & 1 & 1 & 1 & 0 \\
\hline 26 & 0 & 0 & 0 & 0 & 0 & 0 & 0 \\
\hline
\end{tabular}

Table A5 - Transmission Loss Factors

\begin{tabular}{|c|c|}
\hline $\begin{array}{c}\text { Transmission } \\
\text { Line, } z-z^{\prime}\end{array}$ & $\begin{array}{c}\text { Transmission } \\
\text { Loss Factor, } l_{z z^{\prime}}\end{array}$ \\
\hline A-B & 0.0302 \\
\hline B-C & 0.0253 \\
\hline C-E & 0.0496 \\
\hline D-E & 0.0440 \\
\hline E-F & 0.0308 \\
\hline E-G & 0.0651 \\
\hline F-G & 0.0501 \\
\hline G-H & 0.0196 \\
\hline G-J & 0.0376 \\
\hline H-I & 0.0080 \\
\hline I-J & 0.0127 \\
\hline I-K & 0.0254 \\
\hline J-K & 0.0310 \\
\hline
\end{tabular}

Table A6 - Transmission Line Limits

\begin{tabular}{|c|c|c|}
\hline $\begin{array}{c}\text { Transmission } \\
\text { Line, } Z-Z^{\prime}\end{array}$ & $\begin{array}{c}\text { Positive Flow } \\
\text { Limit, } L_{z Z^{\prime}}^{+}(\mathrm{MW})\end{array}$ & $\begin{array}{c}\text { Reverse Flow } \\
\text { Limit, } L_{z Z^{\prime}}^{-}(\mathrm{MW})\end{array}$ \\
\hline A-B & 2900 & 1999 \\
\hline B-C & 1300 & 1300 \\
\hline C-E & 5650 & 1999 \\
\hline D-E & 2650 & 1600 \\
\hline E-F & 3100 & 1999 \\
\hline E-G & 2150 & 1600 \\
\hline F-G & 3475 & 1999 \\
\hline G-H & 5210 & 0 \\
\hline G-J & 1000 & 0 \\
\hline H-I & 8450 & 0 \\
\hline
\end{tabular}




\begin{tabular}{|c|c|c|}
\hline $\mathrm{I}-\mathrm{J}$ & 4450 & 0 \\
\hline $\mathrm{I}-\mathrm{K}$ & 1290 & 530 \\
\hline $\mathrm{J}-\mathrm{K}$ & 235 & 510 \\
\hline
\end{tabular}


[1] J.H. Williams, A. Debenedictis, R. Ghanadan, A. Mahone, J. Moore, W.R.M. Iii, S. Price, M.S. Torn, 2050 : The Pivotal Role of Electricity, 335 (2012) 53-60.

[2] N.L. Panwar, S.C. Kaushik, S. Kothari, Role of renewable energy sources in environmental protection: A review, Renew. Sustain. Energy Rev. 15 (2011) 1513-1524. doi:10.1016/j.rser.2010.11.037.

[3] M.Z. Jacobson, M. a. Delucchi, Providing all global energy with wind, water, and solar power, Part I: Technologies, energy resources, quantities and areas of infrastructure, and materials, Energy Policy. 39 (2011) 1154-1169. doi:10.1016/j.enpol.2010.11.040.

[4] M.Z. Jacobson, R.W. Howarth, M. a. Delucchi, S.R. Scobie, J.M. Barth, M.J. Dvorak, M. Klevze, H. Katkhuda, B. Miranda, N. a. Chowdhury, R. Jones, L. Plano, A.R. Ingraffea, Examining the feasibility of converting New York State's all-purpose energy infrastructure to one using wind, water, and sunlight, Energy Policy. 57 (2013) 585-601. doi:10.1016/j.enpol.2013.02.036.

[5] City of New York, New York City's Pathways to Deep Carbon Reductions, New York, NY, 2013.

[6] P.D. Lund, J. Lindgren, J. Mikkola, J. Salpakari, Review of energy system flexibility measures to enable high levels of variable renewable electricity, Renew. Sustain. Energy Rev. 45 (2015) 785-807. doi:10.1016/j.rser.2015.01.057.

[7] S. Pattanariyankool, L.B. Lave, Optimizing transmission from distant wind farms, Energy Policy. 38 (2010) 2806-2815. doi:10.1016/j.enpol.2010.01.012.

[8] S. Ambec, C. Crampes, Electricity provision with intermittent sources of energy, Resour. Energy Econ. 34 (2012) 319-336. doi:10.1016/j.reseneeco.2012.01.001.

[9] B. Elliston, M. Diesendorf, I. MacGill, Simulations of scenarios with $100 \%$ renewable electricity in the Australian National Electricity Market, Energy Policy. 45 (2012) 606-613. doi:10.1016/j.enpol.2012.03.011.

[10] J.L. Acosta, K. Combe, S.Z. Djokic, I. Hernando-Gil, Performance Assessment of Micro and Small-Scale Wind Turbines in Urban Areas, IEEE Syst. J. 6 (2012) 152-163. doi:10.1109/JSYST.2011.2163025.

[11] T.F. Ishugah, Y. Li, R.Z. Wang, J.K. Kiplagat, Advances in wind energy resource exploitation in urban environment: A review, Renew. Sustain. Energy Rev. 37 (2014) 613-626. doi:10.1016/j.rser.2014.05.053.

[12] A. Yang, Y. Su, C. Wen, Y. Juan, W. Wang, Estimation of wind power generation in dense urban area, Appl. Energy. 171 (2016) 213-230. doi:10.1016/j.apenergy.2016.03.007.

[13] J. Plunkett, P. Mosenthal, S. Nadel, R.N. Elliott, D. Hill, C. Neme, C. Donovan, Energy Efficiency and Renewable Energy Resource Development Potential in New York State, 2003.

[14] Federal Energy Regulatory Commission (FERC), Electric Power Markets: National Overview, (2015). http://www.ferc.gov/market-oversight/mktelectric/overview.asp (accessed December 21, 2015).

[15] G. Rothwell, T. Gomez, Electricity Economics, IEEE Press, Piscataway, N.J., 2003. 
[16] M. Ventosa, Á. Baíllo, A. Ramos, M. Rivier, Electricity market modeling trends, Energy Policy. 33 (2005) 897-913. doi:10.1016/j.enpol.2003.10.013.

[17] R. Van Haaren, V. Fthenakis, GIS-based wind farm site selection using spatial multi-criteria analysis (SMCA): Evaluating the case for New York State, Renew. Sustain. Energy Rev. 15 (2011) 3332-3340. doi:10.1016/j.rser.2011.04.010.

[18] E. Corporation, Eastern Wind Integration and Transmission Study, Energy. SR-550-470 (2010) 1-242. doi:CP-550-46505.

[19] J. Wang, A. Botterud, R. Bessa, H. Keko, L. Carvalho, D. Issicaba, J. Sumaili, V. Miranda, Wind power forecasting uncertainty and unit commitment, Appl. Energy. 88 (2011) 4014-4023. doi:10.1016/j.apenergy.2011.04.011.

[20] J. Apt, P. Jaramillo, Variable Renewable Energy and the Electricity Grid, RFF Press, New York, NY, 2014.

[21] L. Hirth, The market value of variable renewables. The effect of solar wind power variability on their relative price, Energy Econ. 38 (2013) 218-236. doi:10.1016/j.eneco.2013.02.004.

[22] C. Hiroux, M. Saguan, Large-scale wind power in European electricity markets: Time for revisiting support schemes and market designs?, Energy Policy. 38 (2010) 3135-3145. doi:10.1016/j.enpol.2009.07.030.

[23] J. Bushnell, E. Mansur, C. Saravia, Vertical Arrangments, Market Structure, and Competition: An Analysis of Restructured US Electricity Markets, Nber Wp. 13507 (2007) 1-73. doi:10.1257/aer.98.1.237.

[24] B. Saravanan, S. Das, S. Sikri, D.P. Kothari, A solution to the unit commitment problem-a review, Front. Energy. 7 (2013) 223-236. doi:10.1007/s11708013-0240-3.

[25] M. Ahmadigorji, N. Amjady, Optimal dynamic expansion planning of distribution systems considering non-renewable distributed generation using a new heuristic double-stage optimization solution approach, Appl. Energy. 156 (2015) 655-665. doi:10.1016/j.apenergy.2015.07.042.

[26] O.J. Guerra, D.A. Tejada, G. V. Reklaitis, An optimization framework for the integrated planning of generation and transmission expansion in interconnected power systems, Appl. Energy. 170 (2016) 1-21. doi:10.1016/j.apenergy.2016.02.014.

[27] N. Zhang, Z. Hu, B. Shen, S. Dang, J. Zhang, Y. Zhou, A source-grid-load coordinated power planning model considering the integration of wind power generation, Appl. Energy. 168 (2016) 13-24. doi:10.1016/j.apenergy.2016.01.086.

[28] A.L. Zheng, Q.P., Wang, J., and Liu, Stochastic Optimization for Unit Commitment - A Review, IEEE Trans. Power Syst. PP (2014) 1-12. doi:10.1109/TPWRS.2014.2355204.

[29] D. Bertsimas, E. Litvinov, X.A. Sun, J. Zhao, T. Zheng, Adaptive Robust Optimization for the Security Constrained Unit Commitment Problem, Power Syst. IEEE .... 28 (2013) 1-8. doi:10.1109/TPWRS.2012.2205021.

[30] G. Morales-España, J.M. Latorre, A. Ramos, Tight and compact MILP formulation for the thermal unit commitment problem, IEEE Trans. Power Syst. 28 (2013) 4897-4908. doi:10.1109/TPWRS.2013.2251373. 
[31] a. Papavasiliou, S.S. Oren, Multiarea Stochastic Unit Commitment for High Wind Penetration in a Transmission Constrained Network, Oper. Res. 61 (2013) 578-592. doi:10.1287/opre.2013.1174.

[32] B. Howard, M. Waite, Impacts of New York GHG Emissions From Distributed Combined Heat and Power, in: Proc. ASME 2014 8th Int. Conf. Energy Sustain., 2014.

[33] New York Independent System Operator (NYISO), 2014 Reliability Needs Assessment, 2014.

[34] NYISO, NYISO Market and Operational Data, (n.d.).

[35] C. Draxl, A. Clifton, B.M. Hodge, J. McCaa, The Wind Integration National Dataset (WIND) Toolkit, Appl. Energy. 151 (2015) 355-366. doi:10.1016/j.apenergy.2015.03.121.

[36] C. Draxl, B. Hodge, A. Clifton, C. Draxl, B. Hodge, A. Clifton, Overview and Meteorological Validation of the Wind Integration National Dataset Toolkit Overview and Meteorological Validation of the Wind Integration National Dataset Toolkit, (2015).

[37] J. King, A. Clifton, B. Hodge, J. King, Validation of Power Output for the WIND Toolkit Validation of Power Output for the WIND Toolkit, (2014).

[38] U.S. Energy Information Administration, Form EIA-923 Detailed Data, (2012).

[39] N. Blair, A.P. Dobos, J. Freeman, T. Neises, M. Wagner, T. Ferguson, P. Gilman, S. Janzou, System advisor model, sam 2014.1. 14: General description, NREL Rep. No. TP-6A20-61019, Natl. Renew. Energy Lab. Golden, CO. (2014) 13. http://www.nrel.gov/docs/fy14osti/61019.pdf.

[40] M. Pierrot, The Wind Power: Wind Energy Market Intelligence, (2015).

[41] G.M. Masters, Renewable and Efficient Electric Power Systems, John Wiley \& Sons, Inc., Hoboken, NJ, 2004.

[42] International Electrotechnical Commission (IEC), International Standard IEC 61400-1, (2005).

[43] B. Mauch, J. Apt, P.M.S. Carvalho, M.J. Small, An effective method for modeling wind power forecast uncertainty, Energy Syst. 4 (2013) 393-417. doi:http://dx.doi.org/10.1007/s12667-013-0083-3.

[44] G. Grothendieck, Package "nls2," (2013).

[45] R Core Team, R: A language and environment for statistical computing, (2016). http://www.r-project.org/.

[46] New York State, New York State GIS Clearinghouse: NYS Civil Boundaries, (2015).

[47] New York Independent System Operator (NYISO), 2015 Load \& Capacity Data, 2015. doi:10.1017/CB09781107415324.004.

[48] Organisation for Economic Co-operation and Development (OECD) Nucelar Energy Agency, Technical and Economic Aspects of Load Following with Nuclear Power Plants, 2011. http://www.oecdnea.org/ndd/reports/2011/load-following-npp.pdf.

[49] Transmission Developers Inc., Champlain Hudson Power Express, (2016).

[50] American Electric Power (AEP), Transmission Facts, 2008.

[51] Electric Power Research Institute (EPRI) and SAIC, Assessment of Transmission and Distribution Losses in New York State, 2012. 
[52] K. Soetaert, K. Van den Meersche, D. van Oevelen, Package "limSolve," (2014).

[53] U.S. Energy Information Administration, Annual Energy Outlook 2015, Off. Integr. Int. Energy Anal. (2015).

[54] M. Waite, V. Modi, Potential for increased wind-generated electricity utilization using heat pumps in urban areas, Appl. Energy. (2014). doi:10.1016/j.apenergy.2014.04.059.

[55] National Renewable Energy Laboratory (NREL), NREL Wind Prospector, (2016). 